\title{
Overcoming Hurdles in Oxygen Evolution Catalyst Discovery via Codesign
}

\author{
Karun K. Rao," Yungchieh Lai," Lan Zhou, Joel A. Haber, Michal Bajdich,* and John M. Gregoire*
}

Cite This: Chem. Mater. 2022, 34, 899-910

Read Online

ACCESS

山 Metrics \& More

Article Recommendations

Supporting Information

ABSTRACT: The oxygen evolution reaction (OER) is central to several sustainable energy technologies. Catalyst development has largely focused on lowering the overpotential and eliminating reliance on precious metals, revealing stark differences in alkaline and acidic OER. In alkaline electrolyte, precious metal-free catalysts have approached the limiting overpotential from established free energy scaling relationships, and our survey of complex metal oxides shows that this limit can be approached with a broad range of catalysts. In acidic electrolyte, electrochemical instabilities create a dual challenge of a dearth of nonprecious metal OER catalysts with overpotential below $0.5 \mathrm{~V}$ and a high dissolved metals concentration for most precious metal-free

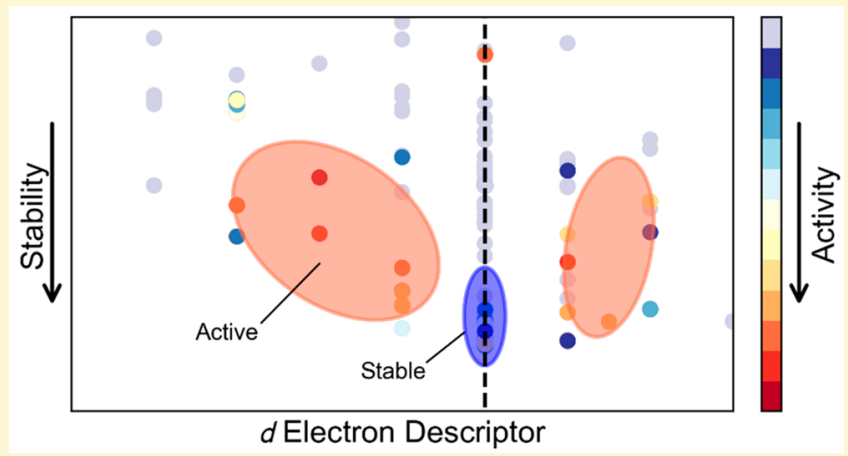
catalysts. On device-relevant time scales, the high dissolved metals concentrations compromise device stability, for example, through a decrease of performance and due to metal exchange between anode and cathode catalysts due to finite permeability of ion exchange membranes. These considerations motivate a substantial increase in monitoring and reporting of dissolved metals concentrations in OER experiments. To facilitate durability-based screening in continued catalyst discovery campaigns, we introduce a durability descriptor based on the $d$-electron count of each metal element compared to that of its Pourbaix-stable oxidation state, which enables rapid down-selection of candidate metal oxide catalysts. We discuss the importance of a codesign approach to catalyst development, where a device architecture can set specific requirements for dissolved metals concentrations and/or cathode and anode catalysts can be designed to tolerate cross-contamination. This devicelevel guidance of basic science will facilitate deployment of new catalysts to meet the societal needs for accelerated sustainable technology development.

\section{INTRODUCTION}

The oxygen evolution reaction (OER) is central to emerging and future technologies ${ }^{1,2}$ such as electrolyzers for $\mathrm{H}_{2}$ production, ${ }^{3,4}$ photoelectrochemical generation of carbon- and nitrogencontaining fuels and chemicals, ${ }^{5-8}$ and air-breathing batteries. ${ }^{9,10}$ We outline the challenges for OER catalyst discovery in acidic electrolytes, ${ }^{11}$ which stand in stark contrast to alkaline electrolytes where there is little room to improve upon the stateof-the-art nonprecious metal catalysts with respect to isolated OER catalyst metrics. These most commonly reported metrics include OER activity and the stability thereof, although catalyst performance must ultimately be considered in the context of a specific target technology and device design, which inherently impose additional considerations and constraints compared to generic catalyst discovery. While traditional catalyst development strives to identify catalysts that improve upon the generic metrics, overcoming technology deployment hurdles motivates rethinking the catalyst design process in the context of codesign.

Codesign for catalysis research aims to generate scientific opportunities from device-level considerations and to facilitate translation of discovered catalysts into devices, ${ }^{12}$ thereby amplifying the impact of catalyst discovery efforts. Embodi- ments of the codesign strategy vary with domain, with the transcendent principle that end-user experiential knowledge should be incorporated throughout the design process; the end user of an electrocatalyst discovery effort is an electrochemical device incorporating the catalyst. Recent technologies developed via codesign include control systems ${ }^{13}$ and computing architectures $^{14}$ where feedback $a b$ initio from the end user disrupted the standard sequential design processes. For electrocatalyst design, codesign motivates development of catalyst discovery workflows based on input from prior data from device operation, multiphysics device models, and new device designs. While trade-offs among multiple performance objectives-activity, stability, and selectivity-are commonly studied in catalysis research, catalyst development traditionally

Received: December 8, 2021

Revised: January 10, 2022

Published: January 24, 2022 
proceeds as a sequential process wherein the findings of the multiobjective optimization are reported for a given catalyst, with subsequent evaluation of the possible device implementations.

Catalyst codesign is not simply a reframing of traditional multiobjective optimization but rather a change in how multiobjective optimization is approached. Many catalyst discovery efforts fall under the umbrella of "use-inspired research", which is commensurate with the codesign philosophy, but the latter is distinguished by the level of specificity in the "inspiration", the disruption of the sequential design of a catalyst and its device implementation, and the development of methods to directly incorporate prior knowledge of device operation in catalyst design. In the present perspective article we do not demonstrate codesign research but rather frame its opportunity in the context of the state of the art for OER in alkaline and acidic electrolytes.

To outline the challenges that may be addressed via codesign, we commence with the high-level considerations of electrolyte $\mathrm{pH}$ and catalyst scalability. Incorporation of bipolar membranes in electrochemical systems has enable the anodic OER reaction to occur in the desired alkaline electrolyte while the cathodic reaction occurs in its most suitable electrolyte, which ranges from near-neutral to acidic conditions for various technologies. $^{8,15-17}$ The bipolar membrane introduces electrochemical potential losses and durability challenges that diminish the benefits of operating OER in alkaline electrolytes, ${ }^{15,18}$ motivating continued efforts to develop active, stable, and scalable OER catalysts for lower-pH operation.

Regarding scalability, the viability of precious metal-based OER catalysts for scalable technologies is debatable, ${ }^{19}$ motivating concepts such as atomically thin coatings and single-atom sites to attempt to address the global scarcity of precious metals. So far, such catalysts have not been sufficient for commercialization, and their long-term durability is challenged by the fact that no catalyst is stable in the absence of dissolved metals species, which are necessary for establishing an equilibrium. $^{20,21}$ The quest for durability is thus not one of eliminating all metal species from the electrolyte but rather finding a catalyst and operating condition where the equilibrium dissolved metals concentrations are not problematic for devicelevel durability. Fully evaluating these requirements must be done in the context of a specific device model, which would enable a more specific implementation of codesign; we present some examples in the Discussion.

An open circuit electrochemical potential corresponds to the thermodynamic condition at which the forward and reverse reaction rates are equal. Analogously, catalyst stability at a given $\mathrm{pH}$ and potential concerns the equilibrium metal concentrations in electrolyte that yields equal rates of corrosion and precipitation, where the corrosion kinetics determine the rate as well as the time-scale of equilibration under a given operating condition, which varies with electrolyte volume and mass transport, e.g., static vs. recirculating electrolyte. The precipitated metals may experience different solid-state binding and are usually more stable and amorphous than their configuration prior to their corrosion. Catalysis research has historically underexplored the study of corrosion equilibration as a dynamic phenomenon that determines the long-term catalyst activity. Pourbaix energetics provide a bulk thermodynamic assessment of the stability of a material at a given electrochemical condition and dissolved metals concentrations, which is useful for comparison among different materials and operating conditions and establishing trends in operational stability. ${ }^{22-26}$

Here, we discuss the opportunities for transformative OER catalyst discoveries based on a combination of recent reports of nonprecious metal electrocatalysts as well as emerging computational and experimental tools that enable the community to reimagine the process for discovering catalysts for OER and other reactions. OER mechanisms, their $\mathrm{pH}$ dependence, and tailoring of electronic structure for improved OER activity have been recently reviewed, ${ }^{27-29}$ motivating our attention on assessing the activity and durability limitations of the state-ofthe-art in precious metal-free electrocatalysts and how they may be addressed with a codesign approach to catalyst discovery guided by the development of new descriptors for Pourbaix stability and OER activity. We highlight the opportunities to consider mutual compatibility of anode and cathode catalysts within a given device to focus discovery efforts on catalyst formulations with maximal downstream impact.

\section{RESULTS}

The state-of-the-art and importance of codesign in OER catalyst discovery varies substantially with operation in alkaline, nearneutral, and acidic electrolytes. In near-neutral conditions, the breadth of the reported catalyst activity and stability is insufficient to establish the trends that we outline below for alkaline and acidic electrolytes. Briefly, cobalt-based catalysts are among the most active catalysts when electrodeposited from electrolytes containing phosphate, methylphosphonate, or borate, at $\mathrm{pH}$ from 7 to 9.2 to form the $\mathrm{Co}-\mathrm{Pi}, \mathrm{Co}-\mathrm{MePi}$, and Co-Bi OER catalyst families. ${ }^{30,31}$ Detailed investigations have shown that operational stability of these catalysts results from a "self-healing" process in which dissolved Co species are redeposited from the electrolyte. ${ }^{32}$ The resulting high dissolved metals concentrations pose challenges for systems-level design. ${ }^{33}$ Other catalysts based on first-row transition metals such as $\mathrm{Ni}$ and $\mathrm{Mn}$ have provided comparable OER activity, ${ }^{34}$ although high overpotentials in near-neutral conditions and other systems-level considerations have driven the community's focus on either strong alkaline or strong acidic electrolytes, which we compare and contrast herein.

Implications of OER Intermediate Free-Energy Scaling Relationships. Before contrasting the state of the art in alkaline and acidic OER, we commence with reviewing the present understanding of reaction mechanisms, the associated adsorption energies of reaction intermediates, and the implications of scaling relationships for limiting overpotential. The general fourproton coupled electron transfer OER mechanism under acidic conditions is

$$
\begin{aligned}
& *+\mathrm{H}_{2} \mathrm{O} \rightarrow \mathrm{OH}^{*}+\mathrm{H}^{+}+\mathrm{e}^{-} \\
& \mathrm{OH}^{*} \rightarrow \mathrm{O}^{*}+\mathrm{H}^{+}+\mathrm{e}^{-} \\
& \mathrm{O}^{*}+\mathrm{H}_{2} \mathrm{O} \rightarrow \mathrm{OOH}^{*}+\mathrm{H}^{+}+\mathrm{e}^{-} \\
& \mathrm{OOH}^{*} \rightarrow \mathrm{O}_{2}+{ }^{*}+\mathrm{H}^{+}+\mathrm{e}^{-}
\end{aligned}
$$

and under alkaline conditions is

$$
\begin{aligned}
& *+\mathrm{OH}^{-} \rightarrow \mathrm{OH}^{*}+\mathrm{e}^{-} \\
& \mathrm{OH}^{-}+\mathrm{OH}^{*} \rightarrow \mathrm{O}^{*}+\mathrm{H}_{2} \mathrm{O}+\mathrm{e}^{-} \\
& \mathrm{O}^{*}+\mathrm{OH}^{-} \rightarrow \mathrm{OOH}^{*}+\mathrm{e}^{-} \\
& \mathrm{OOH}^{*}+\mathrm{OH}^{-} \rightarrow \mathrm{O}_{2}+*+\mathrm{H}_{2} \mathrm{O}+\mathrm{e}^{-}
\end{aligned}
$$


From a thermodynamic perspective, neglecting differences in kinetics, the two mechanisms (eqs 1 and 2) are equivalent under a substitution of $\mathrm{H}_{2} \mathrm{O}_{(\mathrm{l})} \rightleftharpoons \mathrm{H}^{+}{ }_{(\mathrm{aq})}+\mathrm{OH}^{-}(\mathrm{aq})$. Therefore, the binding energies of $\mathrm{O}^{*}, \mathrm{OH}^{*}$, and $\mathrm{OOH}^{*}$ are, in principle, sufficient to fully characterize a surface and predict the catalytic activity at any $\mathrm{pH}$, although a given catalyst electrode often exhibits different surfaces as a function of $\mathrm{pH}$ and potential. In the simplest approach, the free-energy change, $\Delta G$, for each of the four reaction steps is calculated relative to $U_{\mathrm{RHE}}=0 \mathrm{~V}$ at $T=$ $298.15 \mathrm{~K}$ and 1 bar pressure, where the energy of the protonelectron pair is in equilibrium with $\mathrm{H}_{2}(\mathrm{~g})$ as given by the computational hydrogen electrode method, ${ }^{35}$ while $-e U_{\mathrm{RHE}}$ accounts for an applied voltage. The theoretical overpotential associated with OER, a key measure of anode activity, is simply the energy needed to overcome the most unfavorable of the four reaction steps in eqs 1 or 2 as

$$
\begin{aligned}
\eta(\mathrm{V} \text { vs RHE })= & \max \left[\Delta G_{\mathrm{OH}^{*}}, \Delta G_{\mathrm{O}^{*}}-\Delta G_{\mathrm{OH}^{*}}, \Delta G_{\mathrm{OOH}^{*}}-\Delta G_{\mathrm{O}^{*}},\right. \\
& \left.4.92 \mathrm{eV}-\Delta G_{\mathrm{OOH}^{*}}\right] / e-1.23 \mathrm{~V}
\end{aligned}
$$

For most materials, $\Delta G_{\mathrm{OOH}^{*}}$ has been shown to scale by the universal relationship ${ }^{36,37} \Delta G_{\mathrm{OOH}^{*}}=\Delta G_{\mathrm{OH}^{*}}+3.2 \mathrm{eV}$, so the overall overpotential for a catalyst is a function of only two descriptors: $\Delta G_{\mathrm{OH}^{*}}$ and $\Delta G_{\mathrm{O}^{*}}$. Small deviations from this scaling showing reduced slopes have been obtained more recently. ${ }^{38}$ Catalyst activity is generally visualized using the descriptors $\Delta G_{\mathrm{O}^{*}}-\Delta G_{\mathrm{OH}^{*}}$ (for steps 2 and 3) and $\Delta G_{\mathrm{OH}^{*}}$ (for steps 1 and 4), which distinguish separate regions for each potential-limiting step (Figure 1). With the computational hydrogen electrode scheme, the overpotential is calculated on the reversible hydrogen electrode (RHE) scale and does not depend on $\mathrm{pH}$. In cases where the overpotential does have an experimental dependence on $\mathrm{pH}$, the binding energies must be

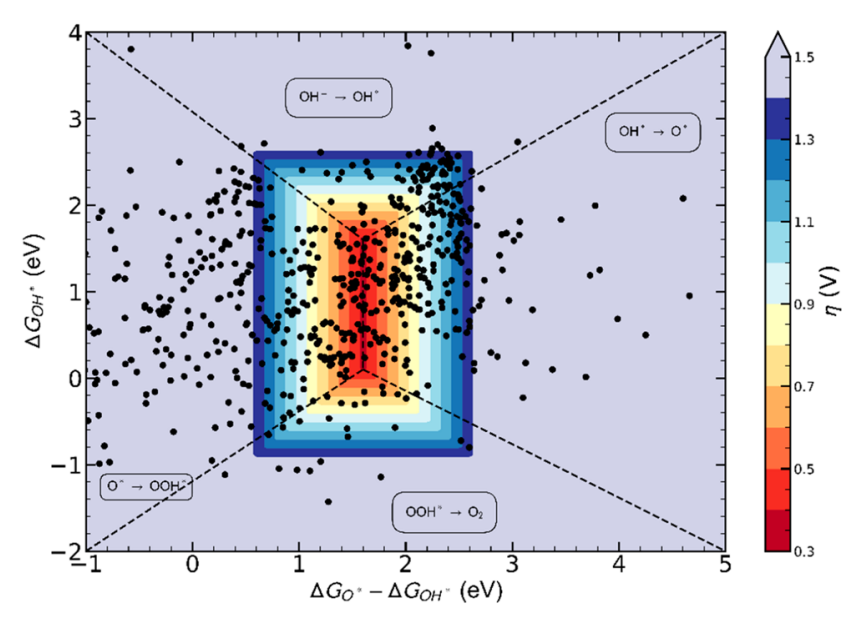

Figure 1. Limiting OER overpotential from eq 1 upon application of the scaling relationship $\Delta G_{\mathrm{OOH}^{*}}=\Delta G_{\mathrm{OH}^{*}}+3.2 \mathrm{eV}$ is shown as a function of the two primary OER activity descriptors, $\Delta G_{\mathrm{OH}^{*}}$ and $\Delta G_{\mathrm{O}^{*}}-\Delta G_{\mathrm{OH}^{*}}$. Four regions are shown corresponding to which of the four elementary steps in the mechanism are rate limiting. The two-dimensional volcano plot results in a minimum overpotential of approximately $0.4 \mathrm{eV}$, although deviations from the scaling relationship, which are typically $\pm 0.1 \mathrm{eV}$, can enable somewhat lower overpotentials for optimal catalysts. Each point corresponds to an ab initio free energy calculation on a catalyst surface, acquired from Catalysis-Hub.org, revealing a handful of catalysts that are within $0.1 \mathrm{eV}$ of the peak of the volcano plot. Realization of a given predicted activity is contingent upon not only the synthesis of the respective catalyst but also its stable operation at the corresponding electrochemical potential in a given electrolyte. corrected based on interactions with the solvent, either explicitly or implicitly, and more recent methods allow for explicit standard hydrogen electrode (SHE)-dependence of the $\Delta G$ values, ${ }^{39,40}$ which are neglected for the purposes of this overview.

The combination of eq 3 and the scaling relationship results in an activity volcano in the binding energy descriptor space with a minimum observable overpotential of $0.378 \mathrm{~V}$ vs RHE (see Figure 1). We plot the calculated $\Delta G_{\mathrm{OH}^{*}}$ and $\Delta G_{\mathrm{O}^{*}}-\Delta G_{\mathrm{OH}^{*}}$ for each material from the CatalysisHub (catalysis-hub.org) database $^{41}$ with additional antimonates from Gunasooriya et al., ${ }^{42}$ which are superimposed with the predicted overpotential to show very few materials near the top of the volcano. There are four distinct regions of the volcano corresponding to which of the four elementary steps is rate limiting. Most materials having either the oxidation of $\mathrm{OH}^{*}$ to $\mathrm{O}^{*}$ or the oxidation of $\mathrm{O}^{*}$ to $\mathrm{OOH}^{*}$ as the rate limiting step and are not limited by the adsorption of $\mathrm{OH}^{-}$or the desorption of $\mathrm{OOH}^{*}$. Deviations from ideal scaling can give calculated overpotentials that approach 0.3 $\mathrm{V}$ vs RHE and are most relevant for materials on the left side of the volcano. The explicit calculated value of $\Delta G_{\mathrm{OOH}^{*}}$ is always used for calculation of $\eta$ in eq 3 when available in the database.

While the descriptors of $\Delta G_{\mathrm{OH}^{*}}$ and $\Delta G_{\mathrm{O}^{*}}-\Delta G_{\mathrm{OH}^{*}}$ give a reasonable prediction of the observed overpotential, this is entirely a surface property, and different facets or sites (e.g., different surface terminations, kinks, step/edge sites) can have a large difference in the estimate of the activity. However, the most active site with reasonable stability will disproportionately contribute to the measured experimental activity, and relative activity trends based on optimum sites have good agreement with experiment. ${ }^{43}$ The most active compounds $(\eta<0.5 \mathrm{~V})$ among those analyzed are based on $\mathrm{Cr}\left(\mathrm{CrO}_{2}, \mathrm{CrOOH}\right)$; $\mathrm{Ir}$ $\left(\mathrm{IrO}_{x}\right)$; $\mathrm{Co}\left(\mathrm{CoOH}, \mathrm{Co}\left(\mathrm{SbO}_{3}\right)_{2}, \mathrm{CoSbO}_{4}, \mathrm{Co}_{2} \mathrm{LiO}_{4}\right)$; or $\mathrm{Ni} / \mathrm{Fe}$ $\left(\mathrm{Ni} / \mathrm{FeOOH}, \mathrm{FeK}_{4} \mathrm{Ni}_{11} \mathrm{H}_{16} \mathrm{O}_{32}\right)$. These materials are consistent with experimental observations of activity ${ }^{44}$ in both acidic and alkaline electrolytes and are discussed in detail below.

Thermodynamic Stabiltiy Trends. Bulk Pourbaix thermodynamics $^{2-26}$ provides a high-level assessment of electrochemical stability which we consider herein to study the relationships between OER overpotential and stability in both acidic and alkaline electrolytes. The Pourbaix energy above the free energy hull ${ }^{45-48}\left(\Delta G_{p b x}\right)$ is the computed Gibbs free energy difference between the bulk phase of interest and the most stable thermodynamic species at a given electrochemical condition, which is defined by the $\mathrm{pH}$, electrochemical potential, and concentrations of dissolved metals species, which are also referred to as "ionic concentrations", although the charge of the metal "ion" may be zero.

Any positive value of $\Delta G_{p b x}$ indicates a thermodynamic driving force toward corrosion, although the maximum tolerable $\Delta G_{p b x}$ for operational stability has not been well established due to three limitations: (i) the bulk thermodynamics do not consider surface energetics, including the specific corrosion thermodynamics at catalytic surface sites; ${ }^{47}$ (ii) an incomplete list of possible aqueous metal species and their uncertainty can underestimate $\Delta G_{p b x}$; and (iii) operational stability can be kinetically realized when the $\Delta G_{p b x}$ is below the free energy barrier for corrosion, which can vary with electrochemical condition and the electrolyte formulation. The $\Delta G_{p b x}$ is typically lowered by $59 \mathrm{meV}$ per decade of dissolved metals concentration (at room temperature), ${ }^{45}$ and in this work, we consider materials with $\Delta G_{p b x}$ less than $1 \mathrm{eV}$ atom ${ }^{-1}$ to be within striking distance of operational stability, i.e., a necessary but 
insufficient criterion for surfaces associated with the materials to be relevant to catalysis (Figure S1). A material with a $\Delta G_{p b x}>1$ $\mathrm{eV} /$ atom that does not exhibit bulk corrosion corresponds to kinetically limited corrosion, typically due to the formation of a self-passivation layer, which would motivate studying the OER overpotential of that passivation layer as opposed to the starting material.

In Figure 2, we evaluate stability trends in both alkaline $(\mathrm{pH}=$ 14) and acidic $(\mathrm{pH}=1)$ conditions through computational

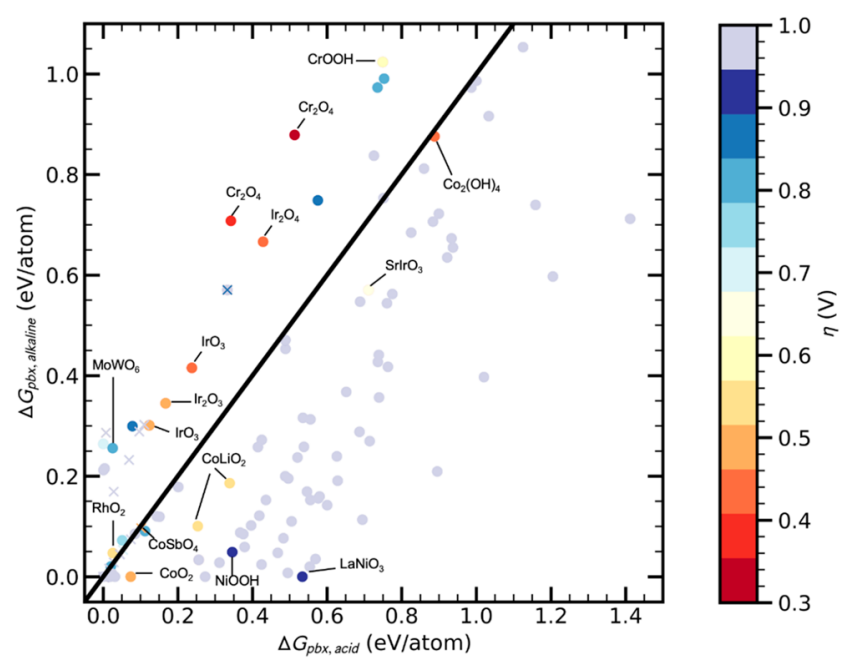

Figure 2. Correlation between calculated alkaline $(\mathrm{pH}=14)$ and acid $(\mathrm{pH}=1)$ stability at an applied potential of $1.5 \mathrm{~V}$ vs RHE. Only materials with computed stability within a physical range of interest $\left(\Delta G_{p b x}<1 \mathrm{eV} /\right.$ atom $)$ are shown. Each point is colored by its computed overpotential based on intermediate binding energies retrieved from Catalysis-Hub.org. Materials with overpotentials less than $0.6 \mathrm{~V}$ are labeled. The parity line, $y=x$, was added as a guide, with points below the parity line indicating better alkaline stability than in acid $\left(\Delta G_{p b x, a c i d}\right.$ $\left.>\Delta G_{p b x, \text { alkaline }}\right)$, and points above the parity line are more stable in acid than in alkaline conditions $\left(\Delta G_{p b x, \text { alkaline }}>\Delta G_{p b x, a c i d}\right)$.

evaluation of $\Delta G_{p b x}$ using the free energies of aqueous metals species assessed from experimental data, a fixed dissolved metals concentration of $10^{-6} \mathrm{M}$, and enthalpy of formations obtained from the Materials Project. ${ }^{26,45,49}$ Data from Catalysis-Hub.org typically include the atomic structures of the surfaces for which adsorption energies were calculated. To identify the corresponding bulk crystal structure, required to calculate a given $\Delta G_{p b x}$, the periodicity perpendicular to the surface plane was analyzed to identify the primitive cell structure. Of the 822 surfaces, the bulk structure could not be identified in 185 entries with active site geometries that cannot be adequately associated with a simple bulk periodic structure, e.g., single atom site substitutions, nanoislands and overlayers, and/or 2D materials. Compositions for an additional 127 bulk structures could not be matched with Materials Project data. Of the remaining 510 surfaces analyzed, 301 (59\%) were within either the acid or alkaline window of $\Delta G_{p b x}<1 \mathrm{eV} /$ atom.

Comparing the stabilities at $\mathrm{pH}=1$ and $\mathrm{pH}=14$, there is a bias toward materials having a greater alkaline stability versus under acidic conditions (below the parity line in Figure 2), with 82 observed materials of which $\mathrm{SrIrO}_{3}, \mathrm{LiCo}_{2} \mathrm{O}_{6}, \mathrm{CoOOH}$, $\mathrm{LaNiO}_{3}, \mathrm{Co}(\mathrm{HO})_{2}, \mathrm{NiOOH}$, and $\mathrm{CoSbO}_{4}$ have $\eta<0.5 \mathrm{~V}$. Greater acid stability than in alkaline (i.e., above parity line) is observed for 40 materials of which only $\mathrm{IrO}_{x}$ and $\mathrm{RuO}$ have $\eta<$ $0.5 \mathrm{~V}$. Finally, 14 materials were equally acid and alkaline stable, with $\mathrm{TiO}_{2}$ among the most stable materials in both acid and base $\left(\Delta G_{p b x}<0.22 \mathrm{eV} /\right.$ atom $)$. All of these are binary oxides, where $\mathrm{RhO}_{2}$ is the only one with calculated OER overpotential below 1 $\mathrm{V}$. This observation of stable binary oxides is discussed below in the context of durability descriptors.

OER in Alkaline Electrolytes. The experimental literature on OER catalysts in alkaline environments is massive, fueled by the relative ease of developing a metal oxide catalyst with substantial OER activity in alkaline electrolyte. ${ }^{50-56}$ Many of the first row transition metals form oxides and oxyhydroxides with excellent Pourbaix stability under alkaline OER conditions and are competent OER catalysts. We conducted high-throughput synthesis and testing of 5198 unique compositions containing different combinations of $\mathrm{Mn}, \mathrm{Fe}, \mathrm{Co}, \mathrm{Ni}, \mathrm{Cu}, \mathrm{Sn}, \mathrm{Ta}, \mathrm{Ce}$, and $\mathrm{La}$ with up to 4 of these elements in each as-synthesized composition at 10 at. \% intervals, as described previously. ${ }^{57}$ Comparing the activity among an equivalent broad range of
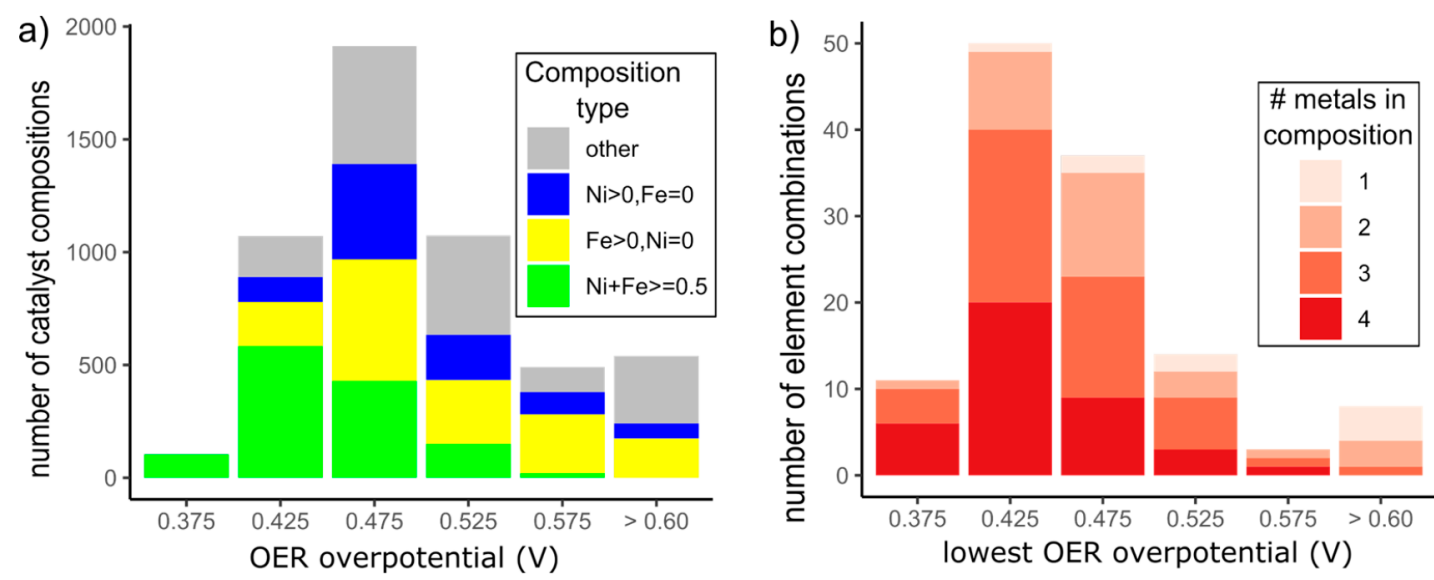

Figure 3. Summary of OER in alkaline electrolyte. (a) Survey of metal oxide catalysts containing $\mathrm{Mn}, \mathrm{Fe}, \mathrm{Co}, \mathrm{Ni}, \mathrm{Cu}, \mathrm{Sn}, \mathrm{Ta}, \mathrm{Ce}$, and/or $\mathrm{La}$ testing in $\mathrm{pH} 13$ electrolyte where the unique catalyst compositions are enumerated for six different ranges of OER overpotential at $10 \mathrm{~mA} \mathrm{~cm}$ measured after 2 $\mathrm{h}$ of operation in flowing electrolyte at $1.7 \mathrm{Vvs}$ RHE. In each overpotential range the colored bars indicate the number of catalyst compositions with the metals concentration being at least $50 \% \mathrm{Ni}$ or $\mathrm{Fe}$, with $\mathrm{Ni}$ but not $\mathrm{Fe}$, with $\mathrm{Fe}$ but not $\mathrm{Ni}$, and all other compositions. (b) The same data is visualized by the unique combinations of metal elements where the lowest overpotential bin is primarily 3- or 4-cation catalysts containing $\mathrm{Ni}$ and $\mathrm{Fe}$ as well as Ce and/or La. 
catalysts reported in the literature is complicated by the heterogeneity in testing conditions, activity metrics, and duration of catalyst operation, but these experimental parameters are well controlled in our high throughput experiments. For present purposes, we consider catalysts operated at $1.7 \mathrm{~V}$ vs RHE for $2 \mathrm{~h}$ and then evaluated for the overpotential required for $10 \mathrm{~mA} \mathrm{~cm} \mathrm{~cm}^{-2}$ geometric current density.

The results are summarized in Figure $3 \mathrm{a}$ where the distribution of overpotentials has a median of $0.487 \mathrm{~V}$, mean of $0.502 \mathrm{~V}$, and standard deviation of $0.073 \mathrm{~V}$. The variation in activity over this huge catalyst composition space is remarkably low. Catalysts with overpotentials above $0.6 \mathrm{~V}$ are mostly compositions that do not contain transition metals. Compositions where $\mathrm{Mn}$ or $\mathrm{Cu}$ are the primary transition metals can also exhibit such low activity, suggesting that any catalyst containing appreciable concentrations of $\mathrm{Ni}, \mathrm{Fe}$, or $\mathrm{Co}$ will exhibit only minor overpotential variation, at least at the moderate current density of $10 \mathrm{~mA} \mathrm{~cm}$. This finding is further emphasized in Figure $3 \mathrm{~b}$ that summarizes how many combinations of elements out of the 123 unique combinations in the study can lead to a given activity.

The lowest overpotential bin in Figure $3 a, b$ is occupied by catalyst compositions containing both $\mathrm{Ni}$ and $\mathrm{Fe}$, which is commensurate with the known excellent activity of ( $\mathrm{Ni}, \mathrm{Fe})$ $\mathrm{OOH}$ catalysts. ${ }^{54,58-60}$ Catalysts having either $\mathrm{Ni}$ or Fe but not both have slightly higher overpotential, although various compositions with other transition metals, especially Co, exhibit a similar activity. The best activity in the $\mathrm{Ni}-\mathrm{Fe}$ system is $\mathrm{Ni}_{0.6} \mathrm{Fe}_{0.4}$ with an overpotential of $0.396 \mathrm{~V}$, and 84 compositions containing additional elements exhibit even higher activity. The top 59 compositions with overpotentials ranging from 0.368 to $0.390 \mathrm{~V}$ all contain $\mathrm{Ce}$ and/or La, which contributes to the several 3- and 4-cation systems comprising the lowest overpotential bin in Figure $3 \mathrm{~b}$ and is in agreement with our previous findings that these elements promote OER in alkaline electrolyte. ${ }^{61,62}$ Figure 3 also indicates a limiting overpotential of approximately $0.36 \mathrm{~V}$ in $\mathrm{pH} 13$ electrolyte, and we note that, due to higher reaction kinetics in $\mathrm{pH} 14$ electrolyte, the limiting overpotential for similar catalysts is approximately $0.3 \mathrm{~V} .^{61,62}$ The observation of many different element combinations providing comparable activity is a statistical demonstration of the existence of the "overpotential wall" established by OER scaling relationships, as summarized in Figure 1.

Slightly lower operational overpotentials may be realized through engineering the active site density, as was recently demonstrated for $\mathrm{Ni}-\mathrm{Fe}-\mathrm{Co}$ catalysts that achieved $10 \mathrm{~mA}$ $\mathrm{cm}^{-2}$ at $0.243 \mathrm{~V}$, or by utilizing highly oxidized Ir-single-atom sites within the $\mathrm{Ni}-\mathrm{Fe}$ catalyst ${ }^{63}$ reaching $0.183 \mathrm{~V}$ at $10 \mathrm{~mA}$ $\mathrm{cm}^{-2}$. A more dramatic increase in the intrinsic activity near the top of the electrochemical volcano requires a different type of reaction mechanism for which the primary opportunities are (i) the development of catalyst wherein multiple sites participate in the pure chemical-step-like reaction to circumvent the scaling relationship of Figure 1 akin to Photosystem II $^{64}$ and/or (ii) a mechanism in which lattice oxygen is a source of one or both oxygen atoms in the evolved $\mathrm{O}_{2}$, which is a sufficiently different mechanism involving a chemical step referred to as lattice OER (LOER) wherein replenishment of the lattice oxygen is required to complete the catalytic cycle. ${ }^{65,66}$ Note that the LOER-type mechanism is an inherently unstable OER mechanism as discussed previously. ${ }^{67}$ While these lines of inquiry may provide a breakthrough at some point, the outlook for OER in alkaline electrolyte is that catalyst optimization will show diminishing returns due to the above scaling relationship. Given that stable catalytic currents can be obtained with many precious-metal-free OER catalysts, the primary opportunity for catalyst development is via codesign where device-level considerations designate target dissolved metals concentrations that guide development of OER catalyst, as described further in the Discussion.

OER in Acidic Electrolytes. We now turn to OER in acid where establishing activity distributions analogous to Figure 3 is untenable due to the propensity for corrosion in strong acid at OER potentials. Benchmarking of a variety of legacy electrocatalysts revealed that those free of precious metals degraded within $2 \mathrm{~h}$ of operation on a rotating disc electrode in $1 \mathrm{M}$ $\mathrm{H}_{2} \mathrm{SO}_{4}$, with only $\mathrm{Ru}$ - and Ir-based catalysts exhibiting OER activity on this time scale. ${ }^{46,55}$ We summarize the recent literature of OER catalysts that have been operated in at least either $0.05 \mathrm{M} \mathrm{H}_{2} \mathrm{SO}_{4}$ or $0.05 \mathrm{M} \mathrm{HClO}_{4}$ in Figure 4. Since

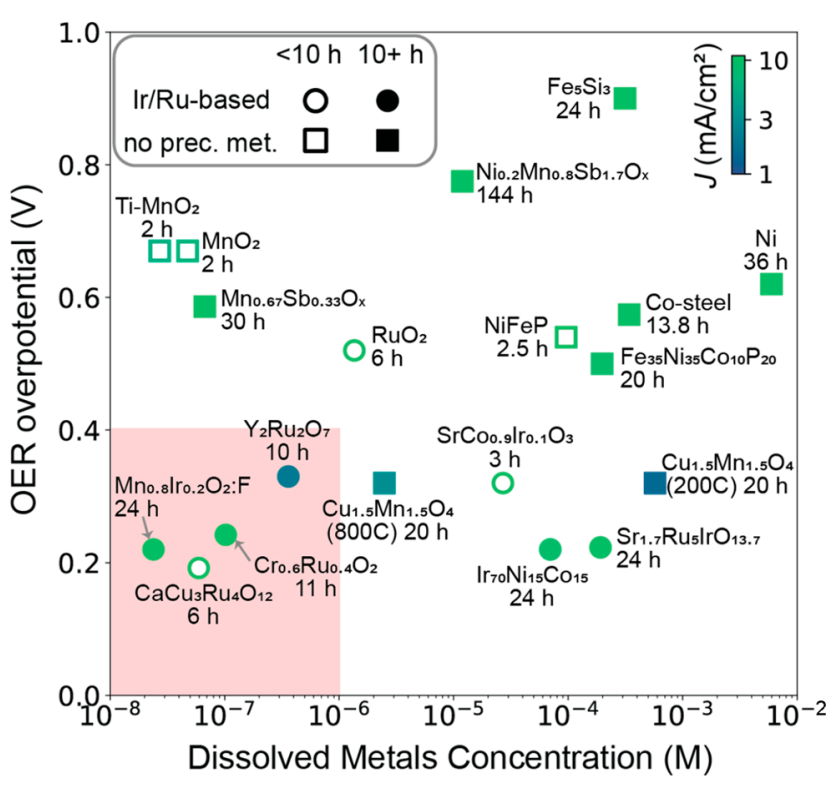

Figure 4. Summary of OER in acid for catalysts with reported overpotential, dissolved metals concentration, and current density after at least $2 \mathrm{~h}$ of operation in aqueous electrolyte with at least $0.05 \mathrm{M}$ of $\mathrm{HClO}_{4}$ or $\mathrm{H}_{2} \mathrm{SO}_{4}$. Co-optimization of activity and stability corresponds to minimizing the overpotential and dissolved metals concentrations, where the desirable, red-shaded region includes only precious metalbased catalysts. The time scale for catalyst equilibration with electrolyte varies not only with the catalyst but also the electrolyte formulation and details of the electrochemical setup, especially anolyte volume and presence/type of membrane. Experiments lasting less than $10 \mathrm{~h}$ are shown with hollow symbols as these are particularly susceptible to not representing steady-state conditions. The circle markers indicate the presence of the precious metals Ir or Ru in the catalyst, whereas the square markers are catalysts reported to be free of precious metals.

stability is the primary concern with operation in acid, we investigate the overpotential at which catalysts operate and the corresponding concentration of dissolved metals species that enables quasi-steady state operation as an OER catalyst. As noted for OER in alkaline conditions, extrinsic catalyst development via engineering of active site density is an effective strategy for scaling the geometric current density, while the primary intrinsic catalyst development challenge is attaining stable operation at any moderate overpotential with low dissolved metals concentration. 
Trends in Figure 4 largely agree with the aforementioned benchmarking study where operation below a $0.5 \mathrm{~V}$ overpotential typically requires $\mathrm{Ru}$ - and Ir-based catalysts. While some of these precious metal catalyst formulations and testing procedures have shown considerable dissolved metals concentrations, ${ }^{68-70}$ operation with concentrations below $10^{-5} \mathrm{M}$ has been demonstrated with Ru-based catalysts, ${ }^{46,71,72}$ and sub-10 $0^{-7}$ $\mathrm{M}$ values have been observed with $\mathrm{CaCu}_{3} \mathrm{Ru}_{4} \mathrm{O}_{12}{ }^{73}$ and $\mathrm{Mn}_{0.8} \mathrm{Ir}_{0.2} \mathrm{O}_{2}$ doped with $\mathrm{F}^{74}$ Comparing the experimental data of Figure 4 to the calculations of Figure 2, consider $\mathrm{MnO}_{2}$ and $\mathrm{Mn}-\mathrm{Sb}$ oxides that have been shown to operate with approximately $10^{-7} \mathrm{M}$ dissolved metals concentration, which is also reflected in the calculated thermodynamic stability where $\Delta G_{p b x, \text { acid }}$ is 0.2 and $0.6 \mathrm{eV} /$ atom, respectively. ${ }^{74}$ Precious metalfree electrocatalysts have generally resulted in high dissolved metals concentrations, as demonstrated by the concentrations in excess of $10^{-4} \mathrm{M}$ for NiFe-based, ${ }^{75,76} \mathrm{Co}-$ steel, $^{77} \mathrm{Ni}^{78}$ and $\mathrm{Fe}_{5} \mathrm{Si}_{3}{ }^{79}$ catalysts. Operation at lower dissolved metals concentrations has recently been demonstrated. The catalyst with the best reported combination of overpotential and metals concentration is a ball-milled, bulk $\mathrm{Cu}_{1.5} \mathrm{Mn}_{1.5} \mathrm{O}_{4}$ catalyst annealed at $800{ }^{\circ} \mathrm{C}$ with a dissolved metals concentration of ca. $2 \times 10^{-5} \mathrm{M}$ after $20 \mathrm{~h}$ of operation. ${ }^{80}$ Annealing the same ballmilled material at $200{ }^{\circ} \mathrm{C}$ results in initially higher activity that degrades faster and results in ca. 200-fold higher dissolved metals concentration. This catalyst warrants further investigation to determine the equilibrium concentration of dissolved metals species and whether the high catalyst loading enables continued corrosion that goes unnoticed on relatively short time scales.

Alternative approaches to increasing catalyst stability include stabilizing transition metals in ternary or quaternary metal oxides, commencing with complementary reports in 2015 of $\mathrm{Ti}$ alloying into rutile $\mathrm{MnO}_{2}$ by Frydendal et al. ${ }^{81}$ and Sb-based alloys ${ }^{82,83}$ developed from initial hits in a high throughput discovery campaign wherein active $\mathrm{Co}$ and $\mathrm{Mn}$ oxides were combined with the acid-stable oxides of $\mathrm{Sb}$ and $\mathrm{Ta} .{ }^{84}$ The $\mathrm{Sb}$ based rutile alloys with the best performance reported to-date are $\mathrm{Ni}_{0.2} \mathrm{Mn}_{0.8} \mathrm{Sb}_{1.7} \mathrm{O}_{z}{ }^{82}$ and $\mathrm{Mn}_{0.67} \mathrm{Sb}_{0.33} \mathrm{O}_{z} \cdot{ }^{83}$ The $\mathrm{Ti}-\mathrm{Mn}$ and $\mathrm{Sb}-\mathrm{Mn}$ systems are particularly promising with dissolved metals species near or below $10^{-7} \mathrm{M}$, although the overpotential remains high and current densities low compared to the precious metal-based electrocatalysts. Expanding upon these successes, a computational screening of Pourbaix stability found that the highly negative formation energy of oxides containing $\mathrm{Sb}$ and transition metals provides improved Pourbaix stability for OER conditions, especially in acidic conditions. ${ }^{42,48}$ For example, a stoichiometric, phase-pure $\mathrm{Co}\left(\mathrm{SbO}_{3}\right)_{2}$ (a.k.a. $\left.\mathrm{CoSb}_{2} \mathrm{O}_{6}\right)$ was reported to exhibit a reasonable OER activity under acidic conditions as well as a high corrosion resistance compared to a stoichiometric $\mathrm{Mn}\left(\mathrm{SbO}_{3}\right)_{2}$ (a.k.a. $\left.\mathrm{MnSb}_{2} \mathrm{O}_{6}\right){ }^{85}$

We perform a similar co-optimization comparison between computed activity and stability for the Catalysis-Hub.org materials. While most materials are either inactive $(>0.5 \mathrm{~V})$ or unstable $\Delta G_{p b x}>1 \mathrm{eV} /$ atom, Figure 5 summarizes 34 catalysts ( $\sim 10 \%$ of those considered) that are moderately active and stable. For each bulk structure, several considered facets and active sites with different calculated overpotentials result in a vertical spread of a given composition within Figure 5. The catalysts that meet the strict constraints of $\eta<0.4 \mathrm{~V}$ and $\Delta G_{p b x, a c i d}<0.4 \mathrm{eV}$ /atom include $\mathrm{CoOOH}, \mathrm{NiOOH}$, and $\mathrm{IrO}_{3}$. While this observation is consistent with experiments on Irbased catalysts (Figure 4), the apparently poor stability of $\mathrm{IrO}_{2}$

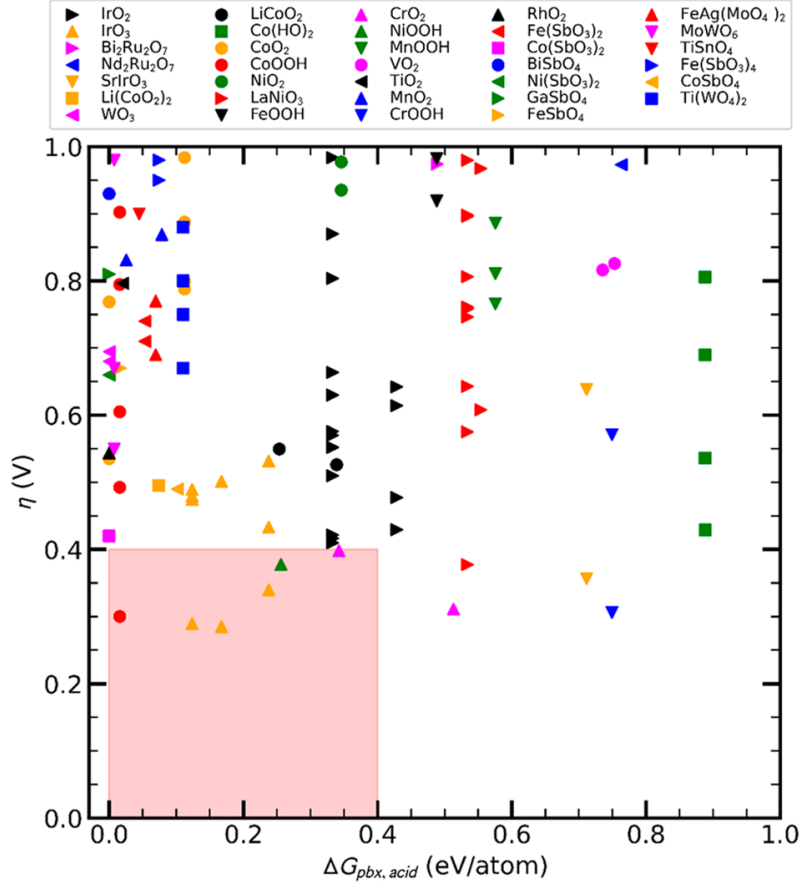

Figure 5. Co-optimization of calculated theoretical overpotential (activity) and calculated thermodynamic stability at $\mathrm{pH}=1$ and $1.5 \mathrm{~V}$ vs RHE for materials in the CatalysisHub database with OER overpotential less than $1 \mathrm{~V}$ and within the experimentally relevant stability range of $\Delta G_{p b x, a c i d}<1 \mathrm{eV} /$ atom. The desired co-optimized region is shaded in red similar to Figure 4, and it contains mostly Ir-based catalyst but also includes $\mathrm{CoOOH}, \mathrm{CrO}_{2}$, and $\mathrm{NiOOH}$.

can be attributed to the use of the end member $\mathrm{IrO}_{4}{ }^{-}$(aq) in the Pourbaix calculation, which provides a significant driving force for corrosion. Ir Pourbaix diagrams calculated with energies from different computational parameters have shown $\mathrm{IrO}_{x}$ to be stable $\left(\Delta G_{p b x}=0\right)$ at $\mathrm{pH}=1$ and $1.5 \mathrm{~V}$ vs RHE. ${ }^{86}$ While the computational settings for Figure 5 may underestimate stability for $\mathrm{IrO}_{2}$, we suspect that for $\mathrm{NiOOH}, \mathrm{CrO}_{2}$, and $\mathrm{CoOOH}$, $\Delta G_{p b x, a c i d}$ systematically overestimates their operational stability because the stable end member in experimental Pourbaix diagrams $\left(\mathrm{Ni}^{2+}(\mathrm{aq}), \mathrm{CrO}_{4}^{-2}(\mathrm{aq})\right.$, and $\left.\mathrm{Co}^{2+}(\mathrm{aq})\right)$ may have a small kinetic barrier for dissolution. Indeed in Figure 4, Ni and Co steel catalysts both have significant observed dissolved metals concentrations. These apparent theory-experiment discrepancies motivate future efforts to refine computational settings to better align with experiments and guide catalyst discovery efforts. Overall, Figure 5 does not exhibit a clear relationship between activity and stability, motivating exploration of additional descriptors to understand and guide the opportunities for the continued development of precious metalfree acidic OER catalysts.

The prevalence of $\mathrm{Ir}, \mathrm{Ru}$, and precious metal-based catalysts and lack of suitable alternatives presented in Figure 5 are largely a reflection on the bias of current data toward studying these high performing systems. This bias is also perpetuated by the exclusion of alternatives to bulk crystal structures including complex binaries, nanoislands, ${ }^{87}$ single atom catalysts, ${ }^{88}$ and $2 \mathrm{D}$ materials, ${ }^{89}$ as mentioned above. Additionally, there are $\mathrm{M}-\mathrm{Sb}-$ $\mathrm{O}_{x}$ materials in Figure 5 that are stable with reasonable activity. $\mathrm{Co}\left(\mathrm{SbO}_{3}\right)_{2}$ is a promising candidate ${ }^{85}$ on the acidic Pourbaix hull $\left(\Delta G_{p b x}=0\right)$ with modest calculated overpotential of $0.41 \mathrm{~V}$ for the (101) surface. Similarly, $\mathrm{Ni}\left(\mathrm{SbO}_{3}\right)_{2}$ also has $\Delta G_{p b x}=0$ 

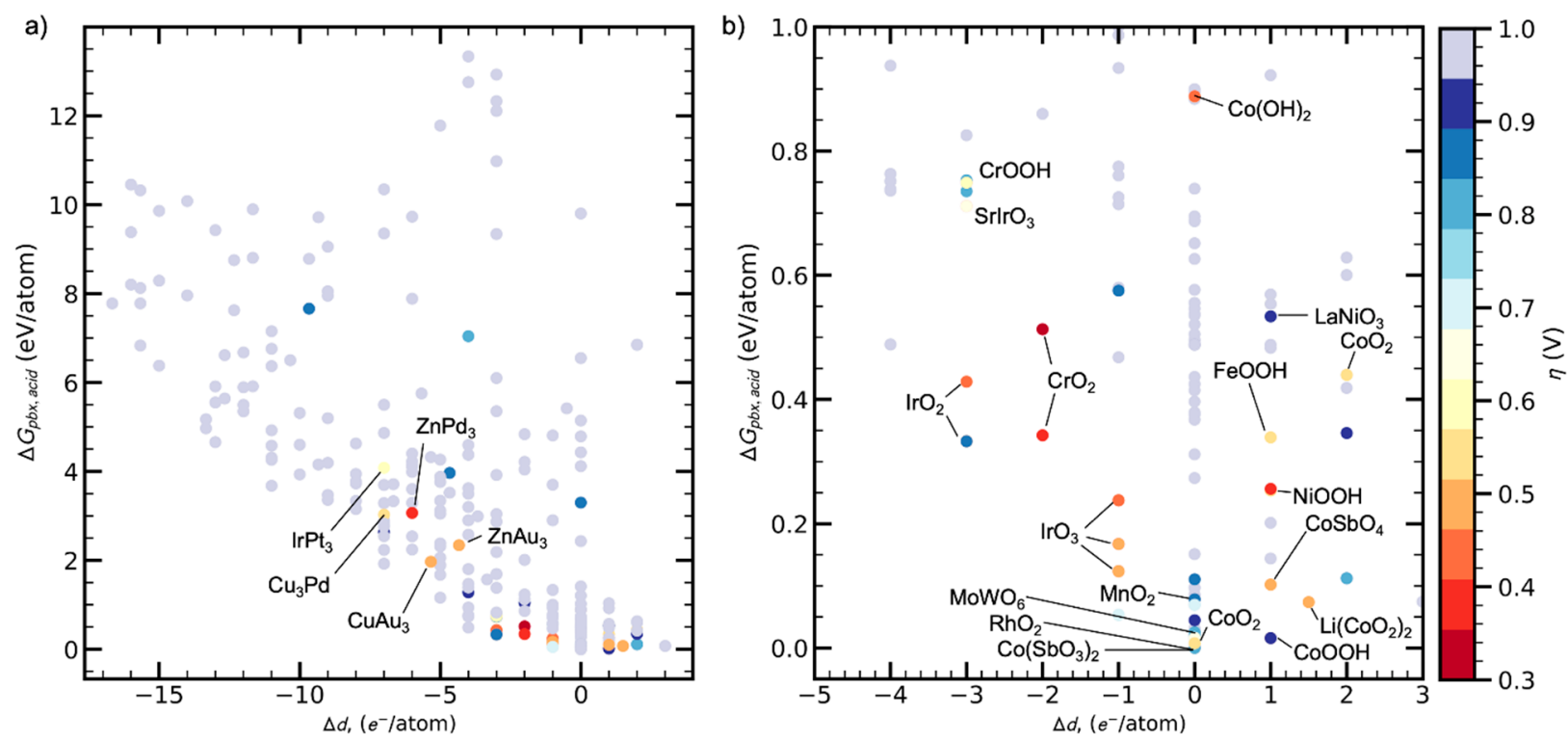

Figure 6. (a) Acid $(\mathrm{pH}=1)$ stability for all computational materials considered in this study, where the quantity $\Delta d$ is identified as a durability descriptor for the minimum attainable $\Delta G_{p b x}$ (b) The same plot is shown for the more desirable region of $\Delta G_{p b x}<1 \mathrm{eV} /$ atom. Colors represent the calculated overpotential, and materials with $\eta<0.6 \mathrm{~V}$ are labeled. The durability descriptor guides future discovery campaigns to focus on materials with $-4 \leq \Delta d \leq 2$.

and an overpotential of $0.66 \mathrm{~V}$ for the (100) surface. ${ }^{42}$ The initial evidence from the experiments in Figure 4 is that compositional modification of stable compounds, such as $\mathrm{Mn}\left(\mathrm{SbO}_{3}\right)_{2}$, can drastically improve the OER overpotential, ${ }^{82,83}$ creating an additional future opportunity for catalyst development via exploration of off-stoichiometric and alloyed variants of the low $\Delta G_{\mathrm{pbx}}$ points in Figure 5. Further research into these categories of materials may address trade-offs between activity and stability.

Durability Descriptors for Acidic OER. The thermodynamic end member for each transition metal element, $m$, of the electrode in the multielement Pourbaix diagram is generally identical to the phase identified in the single-element Pourbaix diagram. For example, in all iridium catalysts under acidic conditions, the iridium atoms are most stable in $\mathrm{IrO}_{4}{ }^{-}(\mathrm{aq})$, or for nickel, the stable end member is $\mathrm{Ni}^{2+}(\mathrm{aq})$. The oxidation state and associated number of $d$-electrons in this end member, defined as $d^{0}$, is an effective reference value correlated to both activity and stability and is tabulated for each transition metal (Table S1). For new multielement phases, the free energy gains are typically small compared to $\Delta G_{p b x}$, while the introduction of a new element expands the set of aqueous species that may establish the Pourbaix hull, which for nontransition metals such as alkali or alkaline earth metals can dramatically increase $\Delta G_{p b x}$ of the solid state material. The combined effect is that the stable Pourbaix domain for a material generally decreases with increasing number of constituent elements. In acid OER conditions, the only multielement stable end domain of a transition metal element is $\mathrm{Bi}_{3} \mathrm{Pt}_{3} \mathrm{O}_{11}$, whereas under alkaline conditions, $\mathrm{Co}, \mathrm{Ni}, \mathrm{Cu}, \mathrm{Zn}, \mathrm{Ta}, \mathrm{Pt}$, and $\mathrm{Au}$ all form multielement stable end domains (Table S1). For some of the transition elements (Fe, Cu, Y, Zr, Ag, Cd, Hf, Ta), the stable Pourbaix domain in alkaline conditions is an oxide, while the domain in acidic conditions is an aqueous ion, which underscores the observation of a larger range of materials exhibiting operational stability in alkaline electrolytes. In contrast, $\mathrm{Mn}$ and $\mathrm{Tc}$ are the only elements to form solid oxides in acidic conditions but aqueous species in alkaline conditions, which highlights the importance of $\mathrm{Mn}$ in the precious metal-free electrocatalysts identified in Figure 4.

Here, we define a descriptor based on the number of $d$ electrons of the cations in the catalyst relative to that in the stable Pourbaix domain. The descriptor is calculated as the sum of the difference in number of $d$-electrons in the catalyst bulk and $d_{0}$ of the end member over all transition metal elements in the bulk catalyst as

$$
\Delta d=\sum_{m=1}^{M} \frac{1}{N_{m}}\left(d_{m}^{0}-d_{m}\right)
$$

where the index, $m$, counts over each element, $d^{0}{ }_{m}$ is the reference number of electrons, and $N_{m}$ is stoichiometric coefficient of the specific element. While $M$ could, in principle, include all elements, oxygen and hydrogen are assumed to always have oxidation states of -2 and +1 , respectively. Furthermore, this metric does not include contributions from non- $d$ block elements, which typically exist in a single oxidation state, have $\Delta d=0$ by definition, and do not typically exhibit electrochemical activity. The choice of our descriptor to only capture the stability of $d$-electron containing cations was also motivated by its simultaneous use as a descriptor of OER activity (see Discussion below). The $\Delta d$ descriptor is equivalent to adding the change in the oxidation states of each transition metal from that in the material to that in the reference end member. It is implemented by assigning formal oxidation states to each element in a probabilistic manner based on the ICSD as defined in Pymatgen ${ }^{90}$ and does not require an $a b$ initio calculation. For example, considering the $\mathrm{La}_{4} \mathrm{Ni}_{4} \mathrm{O}_{12}$ catalyst $\left(M=2, N_{\mathrm{La}}=4, N_{\mathrm{Ni}}\right.$ $=4)$, the formal oxidation states for $\mathrm{La}$ and $\mathrm{Ni}$ are both $+3\left(d_{\mathrm{La}}=\right.$ $0, d_{\mathrm{Ni}}=7$ ) with reference values of $d_{\mathrm{La}}^{0}=0$ and $d_{\mathrm{Ni}}^{0}=8$ to give total value of $\Delta d=1$. A positive (negative) value of $\Delta d$ signifies that the cations are more oxidized (reduced) than the most stable end member.

We observe a strong correlation between our $\Delta d$ descriptor for both the stability and the activity (Figure 6a). As the material is more reduced compared to the end member (negative $\Delta d$ ), 
$\Delta G_{p b x}$ increases and the material becomes less stable. Similarly, materials more oxidized than the end member also decrease the stability compared to the Pourbaix end members. The systems on the oxidized half of the plot tend to contain $\mathrm{Co}\left(\mathrm{CoSbO}_{4}\right.$, $\left.\mathrm{Li}\left(\mathrm{CoO}_{2}\right)_{2}, \mathrm{CoO}_{2}, \mathrm{LiCoO}_{2}\right)$ since the extracted stable end member in acid at $1.5 \mathrm{~V}$ is $\mathrm{Co}^{2+}(\mathrm{aq})$, in agreement with updated experimental Pourbaix data. ${ }^{91}$ Other more oxidized transition metal species with some OER activity $\left(\mathrm{FeOOH}, \mathrm{LaNiO}_{3}\right.$, $\mathrm{NiOOH}$ ) are also present with the corresponding end members in acid as $\mathrm{Fe}^{2+}(\mathrm{aq})$ and $\mathrm{Ni}^{2+}(\mathrm{aq})$, respectively.

The most stable materials (rhodium and ruthenium catalysts) are observed at $\Delta d=0$, which means the active cations are in the same oxidation state as the stable end members. In the restricted region of $\Delta G_{p b x}<1$, the maximum observed $\Delta d$ was -4 , and all materials with $\Delta G_{p b x}<0.05 \mathrm{eV} /$ atom have $\Delta d=0$. The acid stability $\left(\Delta G_{p b x}\right)$ vs $\Delta d$ forms a type of convex hull with respect to our descriptor with minimum at $\Delta d=0$, which provides a lower possible bound on materials stability. This relationship indicates that having the same oxidation state as the end member is a necessary, but not sufficient, criterion for overall stability.

As previously shown in Figure 4, the most active materials $\left(\mathrm{IrO}_{3}, \mathrm{CrO}_{2}, \mathrm{NiOOH}, \mathrm{CoOOH}\right)$ are not considered the most stable, each with $\Delta G_{p b x, a c i d}>0$. When considering activity as a function of our descriptor, the most active materials shown in Figure $6 \mathrm{~b}$ have $\Delta d$ values of $-1,-2$, and -3 . These negative values show that the active cations are more reduced than in their Pourbaix domains, which, while contributing to instability, provide electrons that can participate in effective binding of the OER intermediates. Alternative durability descriptors include the minimum value of $d-d_{0}$ among the $M$ elements (see Figure S2), which alludes to the observation that the prominent contribution to $\Delta G_{p b x}$ is from only the most reduced species. The average $d-d_{0}$ were also considered but did not change the descriptor value for materials with a single cation of those in the range $-4<\Delta d<2$ and are less correlated with $\Delta G_{p b x}$ below this range. The nonzero values of $\Delta d$ describe OER active catalysts and are directly linked to the nonzero outer $d$-electron rule developed previously. ${ }^{92}$

\section{DISCUSSION}

Durability-Based Design of OER Experiments. The synthesis of a precatalyst to generate an active catalyst under operating conditions is a catalyst development strategy that can be intentionally employed but is more often exercised unintentionally. As surface Pourbaix diagrams and surface science experiments continue to elucidate the operational surfaces of catalysts, it appears that practically all synthesized catalysts may be precatalysts. Whether the transformation of precatalysts into its operational form is intentional or unintentional, the dynamic nature of operando heterogeneous electrocatalysts offers several theoretical and experimental challenges and opportunities for catalyst discovery and understanding.

While the computational evaluation of binding energies of faceted crystals has been incredibly valuable for catalyst discovery and understanding (illustrated by Figure 1), most such catalysts cannot be experimentally realized, especially for multimetal catalysts where the equilibrium ratio of different dissolved metals concentrations at a given operating $\mathrm{pH}$ and potential is different than the modeled stoichiometric ratio. Consequently, unless the electrolyte is prepared to contain the appropriate dissolved metals concentrations prior to contact with the catalyst, differential corrosion will occur and change the surface composition, causing a disconnect with the theoretical work on pristine stoichiometric surfaces. At the same time, the undercoordinated sites resulting from corrosion may be more active and only synthesizable through this corrosion pathway, making differential corrosion an avenue for catalyst synthesis, as has been demonstrated in dealloying to form metal nanostructures and in pyrochlore systems. ${ }^{46,93}$

Elevating the reporting standards for catalyst activity to include dissolved metals concentrations would help advance the field. In addition, new types of experiments are needed, including characterization of differential corrosion that alters the surface composition from that of the precatalyst and whether the differential corrosion can be mitigated with tailored dissolved metals concentrations in the electrolyte. Given that techniques such as ICP-MS and ICP-OES are well established for measuring dissolved metals concentrations, the need for technique development lies in the design of electrochemical cells and experiments that enable equilibration of the dissolved metals species with the catalyst electrode. In traditional bulk electrochemical cells, periodic sampling of the electrolyte, which is the source of much of the data in Figure 4, may be sufficient, although electrochemical cells, especially those lacking an ion exchange membrane, may enable metals dissolved from the working electrode to deposit onto the counter electrode. A quasi-steady-state condition of corrosion and deposition on different electrodes via metals transport through the electrolyte may give the appearance of stabilized metals concentrations, which could go unnoticed until the entire working electrode corrodes away. Consequently, the metals concentrations in Figure 4 may be considered as lower limits for the true equilibrated values.

The use of membranes can mitigate the metals transport between electrodes, although ultimately postelectrochemistry characterization of the amount of deposited material on the counter electrode would be a prudent complement to the dissolved metals measurements. The use of flow cells offers two distinct advantages: that the rapid removal of dissolved metals from the electrochemical environment before any such crossover to the counter electrode can occur and that time-resolved measurements can be facilitated. The state of the art is well represented by recent reports from Geiger et al., ${ }^{94}$ Klemm et al., ${ }^{95}$ and Shkirskiy et al., ${ }^{96}$ where dissolved metals concentration measurements at approximately two second intervals provide accelerated screening of corrosion rates. The primary concession of this electrochemical configuration is that the constant replenishment of fresh electrolyte circumvents the equilibration of the metals concentrations in electrolyte.

Codesign of Next-Generation OER Catalysts. While most literature reports of operationally stable electrocatalysts consider durations on the order of 1 to $100 \mathrm{~h}$, when considering device-level stability over a decade, the operational requirements with respect to equilibrium dissolved metals concentrations must be understood and employed in catalyst discovery efforts. Durability descriptors, such as that illustrated in Figure 6, can be used for primary screening in computational catalyst discovery workflows to focus efforts on catalysts most likely to engender long-term operation at low dissolved metals concentrations.

Catalyst codesign arises when considering the implications of the durability, for example, the equilibrium dissolved metals concentration, in a particular device setting. Whereas the corrosion, crossover, and precipitation of metals may go unnoticed in a 3-electrode cell where the influence of the precipitated metals on the counter electrode is typically not measured, the impacts of this corrosion process will be more 
dramatically realized in a 2-electrode configuration. ${ }^{97}$ The use of polymer electrolytes introduces additional stability considerations, which has been most extensively demonstrated in polymer exchange membrane fuel cells wherein degradation occurs via precipitation of dissolved catalysts within the membrane. ${ }^{98}$ Recognizing the interplay of anode, membrane, and cathode stability in an electrochemical device motivates some new approaches to catalyst design. The high-level strategy is to develop anode and cathode catalysts whose dissolved species do not precipitate within the electrolyte and then codevelop anode and cathode catalysts so that their respective long-time-scale corrosion and crossover does not deactivate the opposing catalyst.

One approach for the latter part of this strategy is to use the same metal elements in each catalyst, ${ }^{56}$ although that strategy poses substantial limitations on catalyst chemistry, especially when considering only nonprecious metals. A more general approach is to consider whether the solution species resulting from the corrosion of one catalyst will poison the surface of the opposing catalyst. For example, the anode catalysts could be designed to have a much lower equilibrium dissolved metals concentration under the anode operating condition than under the cathode operating condition, which would mitigate cathode catalyst poisoning. The softer version of this constraint is to consider elements that can be easily stripped from the opposing catalyst, facilitating the design of in situ catalyst regeneration protocols. These codesign-based constraints on the elemental design space for catalyst discovery challenge the status quo of catalyst discovery science while facilitating translation and impact of the discovered catalysts.

\section{CONCLUSIONS}

Codesign of new catalysts for OER inspire our metrics and methods for evaluating OER catalysts under both acid and alkaline conditions. Under alkaline conditions, improvements in precious metal-free catalyst activity and durability are approaching fundamental limits imposed by scaling relationships. Under acidic conditions, device level constraints require limiting the total dissolved metals concentration under operation and highlight the importance of reporting total dissolved metals concentrations in future OER experiments. By summarizing recent materials from literature, coupled with an extensive review of materials reported in large online databases, we identify promising directions to discover new materials that co-optimize activity and durability. We show a simple descriptor based on the number of $d$-electrons in a catalyst can aid in this process to efficiently screen materials in future studies. Devicelevel guidance of catalyst discovery and development will facilitate deployment of new catalysts to meet the societal needs for accelerated sustainable technology development.

\section{ASSOCIATED CONTENT}

\section{SI Supporting Information}

The Supporting Information is available free of charge at https://pubs.acs.org/doi/10.1021/acs.chemmater.1c04120.

Data tables and additional visualizations of activitydurability relationships (PDF)

\section{AUTHOR INFORMATION}

\section{Corresponding Authors}

Michal Bajdich - SUNCAT Center for Interface Science and Catalysis and Liquid Sunlight Alliance, SLAC National
Accelerator Laboratory, Menlo Park, California 94025, United States; (1) orcid.org/0000-0003-1168-8616;

Email: bajdich@slac.stanford.edu

John M. Gregoire - Division of Engineering and Applied Science and Liquid Sunlight Alliance, California Institute of Technology, Pasadena, California 91125, United States; 시이.org/0000-0002-2863-5265; Email: gregoire@ caltech.edu

\section{Authors}

Karun K. Rao - Department of Chemical Engineering, Stanford University, Stanford, California 94305, United States; SUNCAT Center for Interface Science and Catalysis and Liquid Sunlight Alliance, SLAC National Accelerator Laboratory, Menlo Park, California 94025, United States

Yungchieh Lai - Division of Engineering and Applied Science and Liquid Sunlight Alliance, California Institute of Technology, Pasadena, California 91125, United States

Lan Zhou - Division of Engineering and Applied Science and Liquid Sunlight Alliance, California Institute of Technology, Pasadena, California 91125, United States

Joel A. Haber - Division of Engineering and Applied Science and Liquid Sunlight Alliance, California Institute of Technology, Pasadena, California 91125, United States; (1) orcid.org/ 0000-0001-7847-5506

Complete contact information is available at:

https://pubs.acs.org/10.1021/acs.chemmater.1c04120

\section{Author Contributions}

"(K.K.R. and Y.L.) These authors contributed equally. The manuscript was written through contributions of all authors. All authors have given approval to the final version of the manuscript.

\section{Notes}

The authors declare no competing financial interest.

\section{Biographies}

Karun K. Rao is a Postdoctoral Researcher of Theory and Computation at the SUNCAT Center for Interface Science and Catalysis at Stanford/ SLAC National Laboratory. His research interests include combining $\mathrm{ab}$ initio simulations and data science methods to perform computational screening, characterization, and design of novel electrocatalysts and battery materials.

Yungchieh Lai is a Research Engineer in the High Throughput Experimentation group at the California Institute of Technology. His research focuses on developing (photo)electrochemical and analytical chemistry methods to discover materials for solar-fuels applications.

Lan Zhou is a Staff Scientist in the High Throughput Experimentation group at the California Institute of Technology. Her research focuses on developing processes for combinatorial materials synthesis of metals, metal oxides, and mixed anion materials used in solar-fuels applications.

Joel A. Haber is a Member of the Professional Staff at the California Institute of Technology and a Systems and Integration Team PI in the Liquid Sunlight Alliance (LiSA), a U.S. DOE Energy Innovation Hub. His research in LiSA focuses on high throughput/directed materials translation and integration. His expertise is in solid state and precursor chemistry and advanced high throughput techniques for materials discovery for solar fuels systems.

Michal Bajdich is a Full Staff Scientist at the SUNCAT Center for Interface Science and Catalysis SUNCAT center for catalysis at the SLAC National Laboratory. He is also a Durability Team PI in the Liquid Sunlight Alliance (LiSA), a U.S. DOE Energy Innovation Hub. 
His computational studies lead to the understanding of and discovery of electrocatalysis in tandem with experiments, with special focus on earth-abundant metal oxides and related materials. More recently, he has been applying catalysis informatics and machine learning tools. http://suncat.stanford.edu/people/michal-bajdich.

John M. Gregoire is a Research Professor of Applied Physics and Materials Science and leads the High Throughput Experimentation group at the California Institute of Technology. He is also the Team Lead for Photoactive Materials in the Liquid Sunlight Alliance (LiSA), a U.S. DOE Energy Innovation Hub. His research team explores, discovers, and understands energy-related materials via combinatorial and high throughput experimental methods and their integration with materials theory and artificial intelligence. https://gregoire.people. caltech.edu.

\section{ACKNOWLEDGMENTS}

This material is based on work performed by the Liquid Sunlight Alliance, which is supported by the U.S. Department of Energy, Office of Science, Office of Basic Energy Sciences, Fuels from Sunlight Hub, under Award DE-SC0021266.

\section{REFERENCES}

(1) Katsounaros, I.; Cherevko, S.; Zeradjanin, A. R.; Mayrhofer, K. J. J. Oxygen Electrochemistry as a Cornerstone for Sustainable Energy Conversion. Angew. Chem., Int. Ed. 2014, 53 (1), 102-121.

(2) De Luna, P.; Hahn, C.; Higgins, D.; Jaffer, S. A.; Jaramillo, T. F.; Sargent, E. H. What Would It Take for Renewably Powered Electrosynthesis to Displace Petrochemical Processes? Science 2019, 364 (6438), No. eaav3506.

(3) Miller, H. A.; Bouzek, K.; Hnat, J.; Loos, S.; Bernacker, C. I.; Weißgarber, T.; Rontzsch, L.; Meier-Haack, J. Green Hydrogen from Anion Exchange Membrane Water Electrolysis: A Review of Recent Developments in Critical Materials and Operating Conditions. Sustainable Energy \& Fuels 2020, 4 (5), 2114-2133.

(4) Pham, C. V.; Escalera-López, D.; Mayrhofer, K.; Cherevko, S.; Thiele, S. Essentials of High Performance Water Electrolyzers - From Catalyst Layer Materials to Electrode Engineering. Adv. Energy Mater. 2021, 11, 2101998.

(5) Bao, D.; Zhang, Q.; Meng, F.-L.; Zhong, H.-X.; Shi, M.-M.; Zhang, Y.; Yan, J.-M.; Jiang, Q.; Zhang, X.-B. Electrochemical Reduction of N2 under Ambient Conditions for Artificial N2 Fixation and Renewable Energy Storage Using N2/NH3 Cycle. Adv. Mater. 2017, 29 (3), 1604799.

(6) Guo, C.; Ran, J.; Vasileff, A.; Qiao, S.-Z. Rational Design of Electrocatalysts and Photo(Electro)Catalysts for Nitrogen Reduction to Ammonia (NH 3) under Ambient Conditions. Energy Environ. Sci. 2018, $11(1), 45-56$.

(7) Cui, X.; Tang, C.; Zhang, Q. A Review of Electrocatalytic Reduction of Dinitrogen to Ammonia under Ambient Conditions. Adv. Energy Mater. 2018, 8 (22), 1800369.

(8) Zhou, X.; Liu, R.; Sun, K.; Chen, Y.; Verlage, E.; Francis, S. A.; Lewis, N. S.; Xiang, C. Solar-Driven Reduction of 1 Atm of $\mathrm{CO}_{2}$ to Formate at $10 \%$ Energy-Conversion Efficiency by Use of a $\mathrm{TiO}_{2}$ -Protected III-V Tandem Photoanode in Conjunction with a Bipolar Membrane and a Pd/C Cathode. ACS Energy Lett. 2016, 1 (4), 764770 .

(9) Liu, X.; Zhang, G.; Wang, L.; Fu, H. Structural Design Strategy and Active Site Regulation of High-Efficient Bifunctional Oxygen Reaction Electrocatalysts for Zn-Air Battery. Small 2021, 17, 2006766.

(10) Zeng, K.; Zheng, X.; Li, C.; Yan, J.; Tian, J.-H.; Jin, C.; Strasser, P.; Yang, R. Recent Advances in Non-Noble Bifunctional Oxygen Electrocatalysts toward Large-Scale Production. Adv. Funct. Mater. 2020, 30 (27), 2000503.

(11) Reier, T.; Nong, H. N.; Teschner, D.; Schlögl, R.; Strasser, P. Electrocatalytic Oxygen Evolution Reaction in Acidic Environments -
Reaction Mechanisms and Catalysts. Adv. Energy Mater. 2017, 7 (1), 1601275.

(12) Siegmund, D.; Metz, S.; Peinecke, V.; Warner, T. E.; Cremers, C.; Grevé, A.; Smolinka, T.; Segets, D.; Apfel, U.-P. Crossing the Valley of Death: From Fundamental to Applied Research in Electrolysis. JACS Au 2021, 1 (5), 527-535.

(13) Garcia-Sanz, M. Control Co-Design: An Engineering Game Changer. Advanced Control for Applications 2019, 1 (1), No. e18.

(14) Jiang, W.; Xiong, J.; Shi, Y. A Co-Design Framework of Neural Networks and Quantum Circuits towards Quantum Advantage. Nat. Commun. 2021, 12 (1), 579.

(15) Sun, K.; Liu, R.; Chen, Y.; Verlage, E.; Lewis, N. S.; Xiang, C. A Stabilized, Intrinsically Safe, $10 \%$ Efficient, Solar-Driven WaterSplitting Cell Incorporating Earth-Abundant Electrocatalysts with Steady-State PH Gradients and Product Separation Enabled by a Bipolar Membrane. Adv. Energy Mater. 2016, 6 (13), 1600379.

(16) Vargas-Barbosa, N. M.; Geise, G. M.; Hickner, M. A.; Mallouk, T. E. Assessing the Utility of Bipolar Membranes for Use in Photoelectrochemical Water-Splitting Cells. ChemSusChem 2014, 7 (11), 3017-3020.

(17) Ho, A.; Zhou, X.; Han, L.; Sullivan, I.; Karp, C.; Lewis, N. S.; Xiang, C. Decoupling $\mathrm{H}_{2}(\mathrm{~g})$ and $\mathrm{O}_{2}(\mathrm{~g})$ Production in Water Splitting by a Solar-Driven $\mathrm{V}^{3+/ 2+}\left(\mathrm{Aq}, \mathrm{H}_{2} \mathrm{SO}_{4}\right) \mid \mathrm{KOH}(\mathrm{Aq})$ Cell. ACS Energy Lett. 2019, 4 (4), 968-976.

(18) Bui, J. C.; Digdaya, I.; Xiang, C.; Bell, A. T.; Weber, A. Z. Understanding Multi-Ion Transport Mechanisms in Bipolar Membranes. ACS Appl. Mater. Interfaces 2020, 12 (47), 52509-52526.

(19) Taie, Z.; Peng, X.; Kulkarni, D.; Zenyuk, I. V.; Weber, A. Z.; Hagen, C.; Danilovic, N. Pathway to Complete Energy Sector Decarbonization with Available Iridium Resources Using Ultralow Loaded Water Electrolyzers. ACS Appl. Mater. Interfaces 2020, 12 (47), 52701-52712.

(20) She, L.; Zhao, G.; Ma, T.; Chen, J.; Sun, W.; Pan, H. On the Durability of Iridium-Based Electrocatalysts toward the Oxygen Evolution Reaction under Acid Environment. Adv. Funct. Mater. 2021, 2108465.

(21) Shan, J.; Guo, C.; Zhu, Y.; Chen, S.; Song, L.; Jaroniec, M.; Zheng, Y.; Qiao, S.-Z. Charge-Redistribution-Enhanced Nanocrystalline Ru@IrOx Electrocatalysts for Oxygen Evolution in Acidic Media. Chem. 2019, 5 (2), 445-459.

(22) Pourbaix, M. Atlas d'Equilibres Electrochimiques; GauthiersVillars: Paris, 1963.

(23) Cubicciotti, D. Pourbaix Diagrams for Mixed Metal Oxides Chemistry of Copper in BWR Water. CORROSION 1988, 44 (12), 875-880.

(24) Bajdich, M.; García-Mota, M.; Vojvodic, A.; Nørskov, J. K.; Bell, A. T. Theoretical Investigation of the Activity of Cobalt Oxides for the Electrochemical Oxidation of Water. J. Am. Chem. Soc. 2013, 135 (36), 13521-13530.

(25) Castelli, I. E.; Thygesen, K. S.; Jacobsen, K. W. Calculated Pourbaix Diagrams of Cubic Perovskites for Water Splitting: Stability Against Corrosion. Top Catal 2014, 57 (1-4), 265-272.

(26) Persson, K. A.; Waldwick, B.; Lazic, P.; Ceder, G. Prediction of Solid-Aqueous Equilibria: Scheme to Combine First-Principles Calculations of Solids with Experimental Aqueous States. Phys. Rev. B 2012, 85 (23), 235438.

(27) Giordano, L.; Han, B.; Risch, M.; Hong, W. T.; Rao, R. R.; Stoerzinger, K. A.; Shao-Horn, Y. PH Dependence of OER Activity of Oxides: Current and Future Perspectives. Catal. Today 2016, 262, 210.

(28) An, L.; Wei, C.; Lu, M.; Liu, H.; Chen, Y.; Scherer, G. G.; Fisher, A. C.; Xi, P.; Xu, Z. J.; Yan, C.-H. Recent Development of Oxygen Evolution Electrocatalysts in Acidic Environment. Adv. Mater. 2021, 33 (20), 2006328.

(29) Zhang, K.; Zou, R. Advanced Transition Metal-Based OER Electrocatalysts: Current Status, Opportunities, and Challenges. Small 2021, 17 (37), 2100129.

(30) Esswein, A. J.; Surendranath, Y.; Reece, S. Y.; Nocera, D. G. Highly Active Cobalt Phosphate and Borate Based Oxygen Evolving 
Catalysts Operating in Neutral and Natural Waters. Energy Environ. Sci. 2011, 4 (2), 499-504.

(31) Surendranath, Y.; Kanan, M. W.; Nocera, D. G. Mechanistic Studies of the Oxygen Evolution Reaction by a Cobalt-Phosphate Catalyst at Neutral PH. J. Am. Chem. Soc. 2010, 132 (46), 1650116509 .

(32) Lutterman, D. A.; Surendranath, Y.; Nocera, D. G. A Self-Healing Oxygen-Evolving Catalyst. J. Am. Chem. Soc. 2009, 131 (11), 38383839.

(33) Reith, L.; Triana, C. A.; Pazoki, F.; Amiri, M.; Nyman, M.; Patzke, G. R. Unraveling Nanoscale Cobalt Oxide Catalysts for the Oxygen Evolution Reaction: Maximum Performance, Minimum Effort. J. Am. Chem. Soc. 2021, 143 (37), 15022-15038.

(34) Bediako, D. K.; Lassalle-Kaiser, B.; Surendranath, Y.; Yano, J.; Yachandra, V. K.; Nocera, D. G. Structure-Activity Correlations in a Nickel-Borate Oxygen Evolution Catalyst. J. Am. Chem. Soc. 2012, 134 (15), 6801-6809.

(35) Nørskov, J. K.; Rossmeisl, J.; Logadottir, A.; Lindqvist, L.; Kitchin, J. R.; Bligaard, T.; Jónsson, H. Origin of the Overpotential for Oxygen Reduction at a Fuel-Cell Cathode. J. Phys. Chem. B 2004, 108 (46), 17886-17892.

(36) Man, I. C.; Su, H.; Calle-Vallejo, F.; Hansen, H. A.; Martínez, J. I.; Inoglu, N. G.; Kitchin, J.; Jaramillo, T. F.; Nørskov, J. K.; Rossmeisl, J. Universality in Oxygen Evolution Electrocatalysis on Oxide Surfaces. ChemCatChem. 2011, 3 (7), 1159-1165.

(37) Kulkarni, A.; Siahrostami, S.; Patel, A.; Nørskov, J. K. Understanding Catalytic Activity Trends in the Oxygen Reduction Reaction. Chem. Rev. 2018, 118 (5), 2302-2312.

(38) Zhao, Z.; Schlexer Lamoureux, P.; Kulkarni, A.; Bajdich, M. Trends in Oxygen Electrocatalysis of 3 D-Layered (Oxy)(Hydro)Oxides. ChemCatChem. 2019, 11 (15), 3423-3431.

(39) Mathew, K.; Kolluru, V. S. C.; Mula, S.; Steinmann, S. N.; Hennig, R. G. Implicit Self-Consistent Electrolyte Model in PlaneWave Density-Functional Theory. J. Chem. Phys. 2019, 151 (23), 234101.

(40) Hörmann, N. G.; Marzari, N.; Reuter, K. Electrosorption at Metal Surfaces from First Principles. npj Comput. Mater. 2020, 6 (1), $1-10$.

(41) Winther, K. T.; Hoffmann, M. J.; Boes, J. R.; Mamun, O.; Bajdich, M.; Bligaard, T. Catalysis-Hub. Org, an Open Electronic Structure Database for Surface Reactions. Sci. Data 2019, 6 (1), 75.

(42) Gunasooriya, G. T. K. K.; Nørskov, J. K. Analysis of Acid-Stable and Active Oxides for the Oxygen Evolution Reaction. ACS Energy Lett. 2020, 5 (12), 3778-3787.

(43) Seh, Z. W.; Kibsgaard, J.; Dickens, C. F.; Chorkendorff, I.; Nørskov, J. K.; Jaramillo, T. F. Combining Theory and Experiment in Electrocatalysis: Insights into Materials Design. Science 2017, 355 (6321), No. eaad4998.

(44) McCrory, C. C. L.; Jung, S.; Peters, J. C.; Jaramillo, T. F. Benchmarking Heterogeneous Electrocatalysts for the Oxygen Evolution Reaction. J. Am. Chem. Soc. 2013, 135 (45), 16977-16987.

(45) Singh, A. K.; Zhou, L.; Shinde, A.; Suram, S. K.; Montoya, J. H.; Winston, D.; Gregoire, J. M.; Persson, K. A. Electrochemical Stability of Metastable Materials. Chem. Mater. 2017, 29 (23), 10159-10167.

(46) Hubert, M. A.; Patel, A. M.; Gallo, A.; Liu, Y.; Valle, E.; BenNaim, M.; Sanchez, J.; Sokaras, D.; Sinclair, R.; Nørskov, J. K.; King, L. A.; Bajdich, M.; Jaramillo, T. F. Acidic Oxygen Evolution Reaction Activity-Stability Relationships in Ru-Based Pyrochlores. ACS Catal. 2020, 10 (20), 12182-12196.

(47) Patniboon, T.; Hansen, H. A. Acid-Stable and Active M-N-C Catalysts for the Oxygen Reduction Reaction: The Role of Local Structure. ACS Catal. 2021, 11 (21), 13102-13118.

(48) Wang, Z.; Zheng, Y.-R.; Chorkendorff, I.; Nørskov, J. K. AcidStable Oxides for Oxygen Electrocatalysis. ACS Energy Lett. 2020, 5, 2905-2908.

(49) Jain, A.; Ong, S. P.; Hautier, G.; Chen, W.; Richards, W. D.; Dacek, S.; Cholia, S.; Gunter, D.; Skinner, D.; Ceder, G.; Persson, K. A. Commentary: The Materials Project: A Materials Genome Approach to Accelerating Materials Innovation. APL Materials 2013, 1 (1), 011002.
(50) Tahir, M.; Pan, L.; Idrees, F.; Zhang, X.; Wang, L.; Zou, J.-J.; Wang, Z. L. Electrocatalytic Oxygen Evolution Reaction for Energy Conversion and Storage: A Comprehensive Review. Nano Energy 2017, 37, 136-157.

(51) Jamesh, M.-I.; Sun, X. Recent Progress on Earth Abundant Electrocatalysts for Oxygen Evolution Reaction (OER) in Alkaline Medium to Achieve Efficient Water Splitting - A Review. J. Power Sources 2018, 400, 31-68.

(52) Mohammed-Ibrahim, J. A Review on NiFe-Based Electrocatalysts for Efficient Alkaline Oxygen Evolution Reaction. J. Power Sources 2020, 448, 227375.

(53) Jamesh, M.-I.; Harb, M. Tuning the Electronic Structure of the Earth-Abundant Electrocatalysts for Oxygen Evolution Reaction (OER) to Achieve Efficient Alkaline Water Splitting - A Review. Journal of Energy Chemistry 2021, 56, 299-342.

(54) Friebel, D.; Louie, M. W.; Bajdich, M.; Sanwald, K. E.; Cai, Y.; Wise, A. M.; Cheng, M.-J.; Sokaras, D.; Weng, T.-C.; Alonso-Mori, R.; Davis, R. C.; Bargar, J. R.; Nørskov, J. K.; Nilsson, A.; Bell, A. T. Identification of Highly Active $\mathrm{Fe}$ Sites in $(\mathrm{Ni}, \mathrm{Fe}) \mathrm{OOH}$ for Electrocatalytic Water Splitting. J. Am. Chem. Soc. 2015, 137, 1305.

(55) McCrory, C. C. L.; Jung, S.; Ferrer, I. M.; Chatman, S. M.; Peters, J. C.; Jaramillo, T. F. Benchmarking Hydrogen Evolving Reaction and Oxygen Evolving Reaction Electrocatalysts for Solar Water Splitting Devices. J. Am. Chem. Soc. 2015, 137 (13), 4347-4357.

(56) Hona, R. K.; Karki, S. B.; Cao, T.; Mishra, R.; Sterbinsky, G. E.; Ramezanipour, F. Sustainable Oxide Electrocatalyst for Hydrogen- and Oxygen-Evolution Reactions. ACS Catal. 2021, 11, 14605-14614.

(57) Stein, H. S.; Guevarra, D.; Shinde, A.; Jones, R. J. R.; Gregoire, J. M.; Haber, J. A. Functional Mapping Reveals Mechanistic Clusters for OER Catalysis across (Cu-Mn-Ta-Co-Sn-Fe)Ox Composition and $\mathrm{PH}$ Space. Mater. Horiz. 2019, 6 (6), 1251-1258.

(58) Louie, M. W.; Bell, A. T. An Investigation of Thin-Film Ni-Fe Oxide Catalysts for the Electrochemical Evolution of Oxygen. J. Am. Chem. Soc. 2013, 135 (33), 12329-12337.

(59) Trotochaud, L.; Ranney, J. K.; Williams, K. N.; Boettcher, S. W. Solution-Cast Metal Oxide Thin Film Electrocatalysts for Oxygen Evolution. J. Am. Chem. Soc. 2012, 134 (41), 17253-17261.

(60) Trotochaud, L.; Young, S. L.; Ranney, J. K.; Boettcher, S. W. Nickel-Iron Oxyhydroxide Oxygen-Evolution Electrocatalysts: The Role of Intentional and Incidental Iron Incorporation. J. Am. Chem. Soc. 2014, 136 (18), 6744-6753.

(61) Haber, J. A.; Guevarra, D.; Jung, S.; Jin, J.; Gregoire, J. M. Discovery of New Oxygen Evolution Reaction Electrocatalysts by Combinatorial Investigation of the Ni-La-Co-Ce Oxide Composition Space. ChemElectroChem. 2014, 1 (10), 1613-1617.

(62) Haber, J. A.; Cai, Y.; Jung, S.; Xiang, C.; Mitrovic, S.; Jin, J.; Bell, A. T.; Gregoire, J. M. Discovering Ce-Rich Oxygen Evolution Catalysts, from High Throughput Screening to Water Electrolysis. Energy Environ. Sci. 2014, 7 (2), 682-688.

(63) Zheng, X.; Tang, J.; Gallo, A.; Garrido Torres, J. A.; Yu, X.; Athanitis, C. J.; Been, E. M.; Ercius, P.; Mao, H.; Fakra, S. C.; Song, C.; Davis, R. C.; Reimer, J. A.; Vinson, J.; Bajdich, M.; Cui, Y. Origin of Enhanced Water Oxidation Activity in an Iridium Single Atom Anchored on NiFe Oxyhydroxide Catalyst. Proc. Natl. Acad. Sci. U.S.A. 2021, 118 (36), e2101817118.

(64) Wang, V. C.-C. Exploring the Kinetic and Thermodynamic Aspects of Four-Electron Electrochemical Reactions: Electrocatalysis of Oxygen Evolution by Metal Oxides and Biological Systems. Phys. Chem. Chem. Phys. 2016, 18 (32), 22364-22372.

(65) Shi, Z.; Wang, Y.; Li, J.; Wang, X.; Wang, Y.; Li, Y.; Xu, W.; Jiang, Z.; Liu, C.; Xing, W.; Ge, J. Confined Ir Single Sites with Triggered Lattice Oxygen Redox: Toward Boosted and Sustained Water Oxidation Catalysis. Joule 2021, 5 (8), 2164-2176.

(66) Zagalskaya, A.; Evazzade, I.; Alexandrov, V. Ab Initio Thermodynamics and Kinetics of the Lattice Oxygen Evolution Reaction in Iridium Oxides. ACS Energy Lett. 2021, 6 (3), 1124-1133.

(67) Binninger, T.; Mohamed, R.; Waltar, K.; Fabbri, E.; Levecque, P.;

Kötz, R.; Schmidt, T. J. Thermodynamic Explanation of the Universal 
Correlation between Oxygen Evolution Activity and Corrosion of Oxide Catalysts. Sci. Rep. 2015, 5, 12167.

(68) Wen, Y.; Chen, P.; Wang, L.; Li, S.; Wang, Z.; Abed, J.; Mao, X.; Min, Y.; Dinh, C. T.; Luna, P. D.; Huang, R.; Zhang, L.; Wang, L.; Wang, L.; Nielsen, R. J.; Li, H.; Zhuang, T.; Ke, C.; Voznyy, O.; Hu, Y.; Li, Y.; Goddard III, W. A.; Zhang, B.; Peng, H.; Sargent, E. H. Stabilizing Highly Active Ru Sites by Suppressing Lattice Oxygen Participation in Acidic Water Oxidation. J. Am. Chem. Soc. 2021, 143 (17), 6482-6490.

(69) Zhao, Y.; Luo, M.; Chu, S.; Peng, M.; Liu, B.; Wu, Q.; Liu, P.; de Groot, F. M. F.; Tan, Y. 3D Nanoporous Iridium-Based Alloy Microwires for Efficient Oxygen Evolution in Acidic Media. Nano Energy 2019, 59, 146-153.

(70) Chen, Y.; Li, H.; Wang, J.; Du, Y.; Xi, S.; Sun, Y.; Sherburne, M.; Ager, J. W.; Fisher, A. C.; Xu, Z. J. Exceptionally Active Iridium Evolved from a Pseudo-Cubic Perovskite for Oxygen Evolution in Acid. Nat. Commun. 2019, 10 (1), 572.

(71) Laha, S.; Lee, Y.; Podjaski, F.; Weber, D.; Duppel, V.; Schoop, L. M.; Pielnhofer, F.; Scheurer, C.; Müller, K.; Starke, U.; Reuter, K.; Lotsch, B. V. Ruthenium Oxide Nanosheets for Enhanced Oxygen Evolution Catalysis in Acidic Medium. Adv. Energy Mater. 2019, 9 (15), 1803795.

(72) Lin, Y.; Tian, Z.; Zhang, L.; Ma, J.; Jiang, Z.; Deibert, B. J.; Ge, R.; Chen, L. Chromium-Ruthenium Oxide Solid Solution Electrocatalyst for Highly Efficient Oxygen Evolution Reaction in Acidic Media. Nat. Commun. 2019, 10 (1), 162.

(73) Miao, X.; Zhang, L.; Wu, L.; Hu, Z.; Shi, L.; Zhou, S. Quadruple Perovskite Ruthenate as a Highly Efficient Catalyst for Acidic Water Oxidation. Nat. Commun. 2019, 10 (1), 3809.

(74) Ghadge, S. D.; Velikokhatnyi, O. I.; Datta, M. K.; Shanthi, P. M.; Tan, S.; Damodaran, K.; Kumta, P. N. Experimental and Theoretical Validation of High Efficiency and Robust Electrocatalytic Response of One-Dimensional (1D) (Mn,Ir) $\mathrm{O}_{2}: 10 \mathrm{~F}$ Nanorods for the Oxygen Evolution Reaction in PEM-Based Water Electrolysis. ACS Catal. 2019, 9 (3), 2134-2157.

(75) Hu, F.; Zhu, S.; Chen, S.; Li, Y.; Ma, L.; Wu, T.; Zhang, Y.; Wang, C.; Liu, C.; Yang, X.; Song, L.; Yang, X.; Xiong, Y. Amorphous Metallic NiFeP: A Conductive Bulk Material Achieving High Activity for Oxygen Evolution Reaction in Both Alkaline and Acidic Media. Adv. Mater. 2017, 29 (32), 1606570.

(76) Jiang, S.; Zhu, L.; Yang, Z.; Wang, Y. Enhanced Electrocatalytic Performance of FeNiCoP Amorphous Alloys as Oxygen-Evolving Catalysts for Electrolytic Water Splitting Application. Electrochim. Acta 2021, 368, 137618.

(77) Schäfer, H.; Küpper, K.; Müller-Buschbaum, K.; Daum, D.; Steinhart, M.; Wollschläger, J.; Krupp, U.; Schmidt, M.; Han, W.; Stangl, J. Electro-Oxidation of a Cobalt Based Steel in LiOH: A NonNoble Metal Based Electro-Catalyst Suitable for Durable WaterSplitting in an Acidic Milieu. Nanoscale 2017, 9 (45), 17829-17838.

(78) Mondschein, J. S.; Kumar, K.; Holder, C. F.; Seth, K.; Kim, H.; Schaak, R. E. Intermetallic $\mathrm{Ni}_{2}$ Ta Electrocatalyst for the Oxygen Evolution Reaction in Highly Acidic Electrolytes. Inorg. Chem. 2018, 57 (10), 6010-6015.

(79) Shen, B.; He, Y.; He, Z.; Wang, Z.; Jiang, Y.; Gao, H. Porous Fe5Si3 Intermetallic Anode for the Oxygen Evolution Reaction in Acidic Electrolytes. J. Colloid Interface Sci. 2022, 605, 637-647.

(80) Ghadge, S. D.; Datta, M. K.; Velikokhatnyi, O. I.; Kuruba, R.; Shanthi, P. M.; Kumta, P. N. Influence of Defects on Activity-Stability of $\mathrm{Cu}_{1.5} \mathrm{Mn}_{1.5} \mathrm{O}_{4}$ for Acid-Mediated Oxygen Evolution Reaction. J. Electrochem. Soc. 2020, 167 (14), 144511.

(81) Frydendal, R.; Paoli, E. A.; Chorkendorff, I.; Rossmeisl, J.; Stephens, I. E. L. Toward an Active and Stable Catalyst for Oxygen Evolution in Acidic Media: Ti-Stabilized $\mathrm{MnO}_{2}$. Adv. Energy Mater. 2015, 5 (22), 1500991.

(82) Moreno-Hernandez, I. A.; MacFarland, C. A.; Read, C. G.; Papadantonakis, K. M.; Brunschwig, B. S.; Lewis, N. S. Crystalline Nickel Manganese Antimonate as a Stable Water-Oxidation Catalyst in Aqueous 1.0 $\mathrm{M} \mathrm{H}_{2} \mathrm{SO}_{4}$. Energy Environ. Sci. 2017, 10 (10), 21032108.
(83) Zhou, L.; Shinde, A.; Montoya, J. H.; Singh, A.; Gul, S.; Yano, J.; Ye, Y.; Crumlin, E. J.; Richter, M. H.; Cooper, J. K.; Stein, H. S.; Haber, J. A.; Persson, K. A.; Gregoire, J. M. Rutile Alloys in the Mn-Sb-O System Stabilize $\mathrm{Mn}^{3+}$ To Enable Oxygen Evolution in Strong Acid. ACS Catal. 2018, 8 (12), 10938-10948.

(84) Shinde, A.; Jones, R. J. R.; Guevarra, D.; Mitrovic, S.; BecerraStasiewicz, N.; Haber, J. A.; Jin, J.; Gregoire, J. M. High-Throughput Screening for Acid-Stable Oxygen Evolution Electrocatalysts in the (Mn-Co-Ta-Sb)OxComposition Space. Electrocatalysis 2015, 6 (2), 229-236.

(85) Evans, T. A.; Choi, K.-S. Electrochemical Synthesis and Investigation of Stoichiometric, Phase - Pure $\mathrm{CoSb}_{2} \mathrm{O}_{6}$ and $\mathrm{MnSb}_{2}$ $\mathrm{O}_{6}$ Electrodes for the Oxygen Evolution Reaction in Acidic Media. ACS Appl. Energy Mater. 2020, 3 (6), 5563-5571.

(86) Flores, R. A.; Paolucci, C.; Winther, K. T.; Jain, A.; Torres, J. A. G.; Aykol, M.; Montoya, J.; Nørskov, J. K.; Bajdich, M.; Bligaard, T. Active Learning Accelerated Discovery of Stable Iridium Oxide Polymorphs for the Oxygen Evolution Reaction. Chem. Mater. 2020, 32 (13), 5854-5863.

(87) Liu, G.; Karuturi, S. K.; Simonov, A. N.; Fekete, M.; Chen, H.; Nasiri, N.; Le, N. H.; Reddy Narangari, P.; Lysevych, M.; Gengenbach, T. R.; Lowe, A.; Tan, H. H.; Jagadish, C.; Spiccia, L.; Tricoli, A. Robust Sub-Monolayers of Co3O4 Nano-Islands: A Highly Transparent Morphology for Efficient Water Oxidation Catalysis. Adv. Energy Mater. 2016, 6 (15), 1600697.

(88) Lee, W. H.; Ko, Y.-J.; Kim, J.-Y.; Min, B. K.; Hwang, Y. J.; Oh, H.S. Single-Atom Catalysts for the Oxygen Evolution Reaction: Recent Developments and Future Perspectives. Chem. Commun. 2020, 56 (84), 12687-12697.

(89) Liu, X.; Dai, L. Carbon-Based Metal-Free Catalysts. Nat. Rev. Mater. 2016, 1 (11), 1-12.

(90) Hautier, G.; Fischer, C.; Ehrlacher, V.; Jain, A.; Ceder, G. Data Mined Ionic Substitutions for the Discovery of New Compounds. Inorg. Chem. 2011, 50 (2), 656-663.

(91) Chivot, J.; Mendoza, L.; Mansour, C.; Pauporté, T.; Cassir, M. New Insight in the Behaviour of Co-H2O System at $25-150{ }^{\circ} \mathrm{C}$, Based on Revised Pourbaix Diagrams. Corros. Sci. 2008, 50 (1), 62-69.

(92) Calle-Vallejo, F.; Inoglu, N. G.; Su, H.-Y.; Martínez, J. I.; Man, I. C.; Koper, M. T. M.; Kitchin, J. R.; Rossmeisl, J. Number of Outer Electrons as Descriptor for Adsorption Processes on Transition Metals and Their Oxides. Chem. Sci. 2013, 4 (3), 1245-1249.

(93) Li, X.; Chen, Q.; McCue, I.; Snyder, J.; Crozier, P.; Erlebacher, J.; Sieradzki, K. Dealloying of Noble-Metal Alloy Nanoparticles. Nano Lett. 2014, 14 (5), 2569-2577.

(94) Geiger, S.; Kasian, O.; Ledendecker, M.; Pizzutilo, E.; Mingers, A. M.; Fu, W. T.; Diaz-Morales, O.; Li, Z.; Oellers, T.; Fruchter, L.; Ludwig, A.; Mayrhofer, K. J. J.; Koper, M. T. M.; Cherevko, S. The Stability Number as a Metric for Electrocatalyst Stability Benchmarking. Nat. Catal 2018, 1 (7), 508-515.

(95) Klemm, S. O.; Topalov, A. A.; Laska, C. A.; Mayrhofer, K. J. J. Coupling of a High Throughput Microelectrochemical Cell with Online Multielemental Trace Analysis by ICP-MS. Electrochem. Commun. 2011, 13 (12), 1533-1535.

(96) Shkirskiy, V.; Speck, F. D.; Kulyk, N.; Cherevko, S. On the Time Resolution of Electrochemical Scanning Flow Cell Coupled to Downstream Analysis. J. Electrochem. Soc. 2019, 166 (16), H866H870.

(97) Tong, W.; Forster, M.; Dionigi, F.; Dresp, S.; Sadeghi Erami, R.; Strasser, P.; Cowan, A. J.; Farràs, P. Electrolysis of Low-Grade and Saline Surface Water. Nat. Energy 2020, 5 (5), 367-377.

(98) Ren, P.; Pei, P.; Li, Y.; Wu, Z.; Chen, D.; Huang, S. Degradation Mechanisms of Proton Exchange Membrane Fuel Cell under Typical Automotive Operating Conditions. Prog. Energy Combust. Sci. 2020, 80, 100859. 